\title{
Effect of impurities on thermophysical properties and phase behaviour of a CCS stream
}

\author{
Antonin Chapoy ${ }^{\mathrm{a}}$, Mahmoud Nazeri ${ }^{\mathrm{a}}$, Mahdi Kapateh $^{\mathrm{a}}$, Rod Burgass ${ }^{\mathrm{a}}$, \\ Christophe Coquelet ${ }^{\mathrm{b}}$, Bahman Tohidi ${ }^{\mathrm{a}}$
}

\begin{abstract}
${ }^{a}$ Hydrates, Flow Assurance \& Phase Equilibria Group, Institute of Petroleum Engineering, Heriot-Watt University, Edinburgh EH14 4AS, Scotland, UK

${ }^{b}$ MINES ParisTech, CTP-Centre Thermodynamique des Procédés, 35, Rue Saint Honoré, 77305 Fontainebleau, France
\end{abstract}

\begin{abstract}
$\mathrm{CO}_{2}$ obtained by capture process is not $100 \%$ pure and may contain impurities such as $\mathrm{O}_{2}$, $\mathrm{Ar}$, $\mathrm{N}_{2}$ and water. The presence of such impurities in $\mathrm{CO}_{2}$ stream can lead to challenging flow assurance and processing issues. The aim of this communication is to present experimental results on the phase behaviour and thermo-physical properties of carbon dioxide in the presence of $\mathrm{O}_{2}, \mathrm{Ar}, \mathrm{N}_{2}$ and water. The effect of these impurities on density and viscosity were experimentally and theoretically investigated over the range of temperature from 243.15 $\mathrm{K}$ to $423.15 \mathrm{~K}$ up to $150 \mathrm{MPa}$. A corresponding-state viscosity model was developed to predict the viscosity of the stream and a volume corrected equation of state approach was used to calculate densities. Saturation pressures and the hydrate stability (in water saturated and under-saturated conditions) of the CCS stream were also experimentally determined and modelled. It is demonstrated that the thermodynamic models and approaches were able to satisfactorily describe the thermophysical properties and phase behaviour of this $\mathrm{CO}_{2}$-rich stream.
\end{abstract}

Keywords: Carbon Dioxide; CCS; Phase Behaviour; Density; Viscosity; Hydrate; Thermodynamic Modelling

\footnotetext{
${ }^{*}$ Corresponding author. Tel.: + 441314513797

E-mail address: antonin.chapoy@ pet.hw.ac.uk
} 


\section{Highlights}

$>$ Density and viscosity of a $\mathrm{CO}_{2}$ rich stream at 243 to $423 \mathrm{~K}$ and up to $150 \mathrm{MPa}$

$>$ Saturation pressures were measured

$>$ Experimental water saturated and undersaturated hydrate data were measured

$>$ Developed models were independently validated using the experimental data 


\section{Introduction}

Carbon Capture and Storage (CCS) is presently being studied as one of several options against the increasing anthropogenic $\mathrm{CO}_{2}$ emissions from the burning of fossil fuels. A CCS chain will consist of three main components: Capture, Transport and Storage. Depending on the capture processes, the flue gases are likely to contain various contaminants/impurities and compositions of these contaminants (de Visser et al., 2008). The presence of these impurities could lead to challenging operating and engineering issues all over the CCS chain, such as safety and toxicity, pressure and compression requirement, dehydration requirement, etc...The properties of a $\mathrm{CO}_{2}$-rich captured stream may differ significantly from pure $\mathrm{CO}_{2}$. No experimental data are currently available for such fluids in the open literature for validation of existing models.

For an oxyfuel combustion power plant, the main contaminants would be argon (Ar), nitrogen $\left(\mathrm{N}_{2}\right)$, oxygen $\left(\mathrm{O}_{2}\right)$ and water $\left(\mathrm{H}_{2} \mathrm{O}\right)$. These impurities were selected for studies in this communication. To avoid two-phase flow and also to increase the density of the system, CCS streams are planned to be transported as liquid or dense phase, therefore knowledge of the phase envelope of CCS is essential. In this paper, saturation pressures of a multicomponent rich $\mathrm{CO}_{2}$ mixture were measured from 253 to $293 \mathrm{~K}$. Water is also expected to be present in the stream, knowledge of the maximum allowable water content in $\mathrm{CO}_{2}$-rich fluids is critical for safe transport of $\mathrm{CO}_{2}$ to storage sites. The presence of water may result in corrosion, ice and/or gas hydrate formation and pipeline blockage, so the fluid system should meet certain dehydration requirements. Experimental measurements of the locus of incipient hydrate-liquid water-vapour curve for the mixture in equilibrium with liquid water are 
presented herein up to $36 \mathrm{MPa}$ and new experimental data are reported for the water content of in the liquid region in equilibrium with hydrates at $15 \mathrm{MPa}$ and temperatures range from 233.15 to 283.15 K. Density and viscosity of the mixture were also measured from 243.15 to 423.15 $\mathrm{K}$ at pressure up to $150 \mathrm{MPa}$.

The Cubic-Plus-Association (CPA-EoS) or the Soave-Redlich-Kwong (SRK) equation of state combined with the solid solution theory of van der Waals and Platteeuw (1959) as developed by Parrish and Prausnitz (1972) was employed to model the fluid and hydrate phase equilibria as previously described by Chapoy et al. (2012). The thermodynamic model was used to predict and compared the properties experimentally obtained (saturation pressure, hydrates). The thermodynamic model was further developed by introducing a volume correction factor for density calculation. A corresponding state model was also developed to predict viscosity of the $\mathrm{CO}_{2}$-rich stream.

\section{Experimental section}

\subsection{Materials}

Carbon dioxide $\left(\mathrm{CO}_{2}\right)$ was purchased from BOC and has a certified purity higher than 99.995 vol\%. Composition of the $\mathrm{CO}_{2}$-rich synthetic mixtures prepared by BOC is given in Table 1 . De-ionized water was used in all hydrate tests

\subsection{Saturation Pressure Measurements and Procedures}

The experimental set-up used consisted of an equilibrium cell, cryostat, rocking/pivot mechanism, and temperature/pressure recording equipment controlled by a PC (Fig 1). The equilibrium cell is a piston-type variable volume (maximum effective volume of $300 \mathrm{ml}$ ), titanium cylindrical pressure vessel with mixing ball, mounted on a horizontal pivot with associated stand for pneumatic controlled rocking through 180 degrees. Rocking of the cell, 
and the subsequent movement of the mixing ball within it, ensures adequate mixing of the cell fluids. For the tests reported here, the cell was rocked through 180 degrees at a rate of 7 times per minute. Cell volume, hence pressure, can be adjusted by injecting/withdrawal of liquid behind the moving piston.

The rig has a working temperature range of 183 to $373 \mathrm{~K}$, with a maximum operating pressure of $70 \mathrm{MPa}$. System temperature is controlled by circulating coolant from a cryostat within a jacket surrounding the cell. The cryostat is capable of maintaining the cell temperature stability to within better than $0.05 \mathrm{~K}$. To achieve good temperature stability, the jacket is insulated with polystyrene boards, while the connecting pipe work is covered with plastic insulationfoam. The temperature is measured and monitored by means of a PRT (Platinum Resistance Thermometers) located within the cooling jacket of the cell, which is calibrated regularly against a Prema 3040 precision thermometer. Cell temperature can be measured with an accuracy of $\pm 0.05 \mathrm{~K}$. A Quartzdyne pressure transducer with an accuracy of $\pm 0.04 \mathrm{MPa}$ was used to monitor pressure. Temperature and Pressure are monitored and recorded by the PC through an RS 232 serial port.

A typical test to determine the bubble point of the mixture is as follows: The cell was charged with the test sample and set to the desired temperature for the measurement. The sample volume was then reduced by pumping liquid into the cell (behind the moving piston), at the opposite end to the sample. By this means the sample pressure was increased such that the sample was at a pressure significantly higher than the expected bubble point pressure. The cell was then rocked to mix the contents and ensure equilibrium. The sample volume was then increased step-wise by removing measured quantities of the pumped liquid behind the piston. At each step mixing was continued until equilibrium was achieved, indicated by a constant pressure. The stabilised equilibrium pressures and change in sample volumes were plotted and the bubble point was indicated by a sharp change in the pressure versus volume 
plot. An example is shown in Fig. 2. As can be seen from Fig.2 the bubble point is easy to identify with an accuracy of $\pm 0.03 \mathrm{MPa}$.

\subsection{Hydrate Dissociation Measurements and Procedures}

Dissociation point measurements were conducted using the isochoric step-heating method developed in this laboratory, which has previously been demonstrated as being considerably more reliable and repeatable than conventional continuous heating and/or visual techniques (Tohidi et al., 2000). Figure 3 shows the apparatus used to determine the phase equilibrium conditions. The phase equilibrium is achieved in a cylindrical cell made of Hastelloy. The cell volume is about $80 \mathrm{~cm} 3$ and it can be operated up to $40 \mathrm{MPa}$ between $243 \mathrm{~K}$ and $323 \mathrm{~K}$. A detailed description of the apparatus and test procedure can be found elsewhere (Haghighi et al., 2009). The weight of fluids (i.e. water and the multicomponent $\mathrm{CO}_{2}$ fluid) injected are recorded prior to any measurements and the overall feed can be calculated.

\subsection{Water Content Measurements and Procedures}

The core of the equipment for water content has been originally described by Chapoy et al. (2012), the setup is comprised of an equilibrium cell and a set-up for measuring the water content of equilibrated fluids passed from the cell. The equilibrium cell is similar to the one described in the saturation pressure measurements (Fig. 1)

The moisture content set-up is comprised of a heated line, a Tuneable diode laser adsorption Spectroscopy (TDLAS) and a flow meter. The tuneable diode laser absorption spectroscopy (TDLAS) for accurate water content measurements has been purchased from Yokogawa. The unit is constructed of polished Monel and thus can be used with corrosive gases such as $\mathrm{H}_{2} \mathrm{~S}$. The set-up is such that a tuned infrared source is passed through the test sample to a detector. The measurement of water content is based upon true peak area and therefore, unlike other units which use peak height, it is not influenced by changes in background gas. 
The unit has two measurement ranges 0-100 ppmV and 0-3000 ppmV, both having a stated accuracy of $\pm 1 \%$ of full scale.

At the start of the test around $10 \mathrm{ml}$ of $0.1 \mathrm{~mm}$ glass beads are placed in a cup shaped depression in the top of the piston. $5 \mathrm{ml}$ of deionised water was then mixed with the glass beads. The glass beads have been found to aid in formation and dissociation of hydrates in previous work, helping to achieve equilibrium. The cell was then closed and the temperature reduced to $263.15 \mathrm{~K}$ and evacuated before injecting pure $\mathrm{CO}_{2}$ or the multicomponent mixture. The cell temperature and pressure were then adjusted to achieve the desired test conditions. The cell temperature was then cycled to lower and higher temperatures than the set point over at least 20 hours. This was confirmed as being sufficient time for equilibrium to be achieved by conducting water content measurements over a number of days in one test. It was found that the water content remained stable.

The key to getting a reliable and stable water content measurement was to achieve a steady flow rate of equilibrated sample through the measurement set-up. The top cell valve was sufficiently opened to achieve a flow rate of between 0.5 and 1 litre per minute through the hygrometer at the same time nitrogen was introduced into the base of the cell in order to maintain the pressure constant. The water content reading from the TDLAS was then monitored until it was stable for at least 10 minutes. This was then taken as the moisture content of the equilibrated fluid passing from the cell. During sampling the heated line was maintained at a temperature of $368.15 \mathrm{~K}$. The repeatability was found to be good, within the estimated experimental accuracy of \pm 5 ppm mole.

\subsection{Viscosity and Density Measurements}

\subsubsection{Experimental Apparatus}


All viscosity measurements were conducted in an in-house designed and constructed set-up, a schematic view is shown in Figure 4. This setup has been designed to have a maximum working pressure of $200 \mathrm{MPa}$ and a maximum working temperature of $523.15 \mathrm{~K}$. The set-up is located inside the chamber of an oven, manufactured by BINDER GmbH, capable of being used at temperatures from 203.15 to $473.15 \mathrm{~K}$.

The set-up is comprised of two small cylinders, with volumes of $25 \mathrm{~cm}^{3}$, connected to each other through a capillary tube with measured length of 14.781 metres and a calculated internal diameter of $0.29478 \mathrm{~mm}$. An oscillating U tube densitometer Anton Paar DMA-HPM is connected to the set-up. The measuring cell contains a U-shaped Hastelloy C-276 tube that is excited to vibrate at its characteristic frequency electronically. The DMA-HPM is connected to a mPDS $2000 \mathrm{~V} 3$ evaluation unit which measures the period of oscillation with a resolution of seven significant digits. The temperature of the vibrating tube cell is measured by a built-in thermometer connected to the mPDS 2000V3 unit. Two three-way valves, one on top of the cylinders connected to capillary tube and one on top of the densitometer, are installed to inject the sample inside the cylinders, tube system and densitometer. The base side of the two cylinders are connected to opposite sides of a push-pull, motor driven mercury pump. This pump can move the sample fluid forwards and backwards between the two cylinders. There is also a hand pump connected to the system to control the pressure of the entire fluid system by injection and withdrawal of mercury. Both the opposed piston pump and the hand pump are fitted with Mitutoyo linear transducers readable to $0.005 \mathrm{~mm}$ on Mitutoyo SD-D1E readouts. As a $1 \mathrm{~mm}$ movement represents $0.151 \mathrm{~cm}^{3}$ displacement in both pumps, the readability is $0.000755 \mathrm{~cm}^{3}$. The opposed piston pump has a variable control with which the speed can be adjusted to a maximum of $5 \mathrm{~cm}^{3} / \mathrm{sec}$. The rate can be set with an error margin of $\pm 0.00003 \mathrm{~cm}^{3} / \mathrm{sec}$. 


\subsubsection{Procedures}

The capillary tube viscosity measurement method has been employed to measure the viscosity of $\mathrm{CO}_{2}$ systems with impurities. In each test, the set-up was loaded with the sample mixtures through the injection point on top of the densitometer after vacuuming the entire system. After disconnecting the sample cylinder from the system, the sample fluid was pushed through the capillary tube into the other cylinder using the push-pull mercury pump. The temperature of the system was set to the desired condition and the desired pressure was set using the hand pump. Once conditions had stabilised after isolating the densitometer by closing the related valve the sample was pumped through the capillary tube at a number of flow rates. To ensure the consistency of the measurements, at each pressure, viscosities were determined at two or three different flow rates and at each flow rate three readings were logged, so the reported viscosity data in this study are an average of at least six or nine separate readings.

Pumping the sample fluid through the capillary tube by the piston pump resulted in a dynamic differential pressure that was monitored and recorded until stable. The pump was then stopped to record the static differential pressure. The difference between the dynamic and static differential pressure was used as the pressure drop across the tube. To ensure laminar flow conditions, Reynolds numbers were checked for the flow rates in which the measurements were performed. The Poiseuille equation, Eq (1), can relate the pressure drop across the capillary tube to the viscosity, tube characteristics and also flow rate for laminar flow:

$\Delta \mathrm{P}=\frac{128 \mathrm{LQ} \pi}{\mathrm{C} \pi \mathrm{D}^{4}}$

Where, $\Delta P$ is differential pressure across the capillary tube viscometer in psi, $Q$ represents flow rate in $\mathrm{cm}^{3} / \mathrm{sec}, L$ is length of the capillary tube in $\mathrm{cm}$, D refers to internal diameter of 
the capillary tube $(0.029478 \mathrm{~cm}), \eta$ is viscosity of the flown fluid in $\mathrm{cP}$ and $C$ is the unit conversion factor equal to 6894757 if the above units are used.

The internal diameter of the tube was calculated by knowing the length and volume of the tube. The tube length changes with temperature but this had no noticeable influence on the obtained viscosity. The set flow rate has no effect on the accuracy of the viscosity measurement. Only differential pressure as a variable in the above formulation can cause error in viscosity measurement. The usual variation in differential pressure measurement is $0.01 \mathrm{psi}$ and this leads to $\pm 1 \%$ of error in the calculated viscosity for those measured in this study.

Density measurements were performed when the temperature of the vibrating tube became stable. Once conditions had stabilised, the oscillation period of the U-tube was determined from the interface mPDS $2000 \mathrm{~V} 3$ evaluation unit. The measurement of density with a vibrating tube densitometer is not absolute, thus, the raw data (period of oscillation) was be further treated to obtain the densities. The relationship (Eq (2)) between them is:

$\rho\left(T_{y} P\right)=A\left(T_{y} P\right) \tau^{2}\left(T_{y} P\right)-B\left(T_{y} P\right)$

where $\rho(T, P)$ is the sample density at temperature $T$ and pressure $P, \tau(T, P)$ is the period of oscillation at temperature and pressure, $A(T, P)$ and $B(T, P)$ are the apparatus parameters depending on temperature and pressure, and they must be determined from calibration measurements. In our calibration, $\mathrm{CO}_{2}$ density is used as a reference substance at two different pressures (the lowest and the highest desired pressures in the system at the same temperature) in gas, liquid and supercritical phases. The apparatus parameters were defined as follows:

$$
\begin{aligned}
& A\left(T_{y} P\right)=\frac{\rho\left(T_{0} P_{1}\right)-\rho\left(T_{n} P_{2}\right)}{\tau^{2}\left(T_{0} P_{1}\right)-\tau^{2}\left(T_{0} P_{2}\right)} \\
& B\left(T_{y} P\right)=\frac{\tau^{2}\left(T_{3} P_{2}\right) \rho\left(T_{0} P_{1}\right)-\tau^{2}\left(T_{0} P_{1}\right) p\left(T_{0} P_{2}\right)}{\tau^{2}\left(T_{0} P_{1}\right)-\tau^{2}\left(T_{0} P_{2}\right)}
\end{aligned}
$$




\section{Thermodynamic and viscosity modelling}

\subsection{Phase Equilibria Model}

A detailed description of the original thermodynamic framework used in this work can be found elsewhere. In summary, the thermodynamic model based on the uniformity of fugacity of each component throughout all the phases is extended to model the equilibrium conditions. The CPA-EoS or the SRK-EoS (if no water is present) are used to determine the component fugacities in fluid phases. The hydrate phase is modelled using the solid solution theory of van der Waals and Platteeuw (1954) as developed by Parrish and Prausnitz (1972). The critical properties of the components used in this work and the CPA parameters for water are given in Table 2 and Table 3, respectively. The non-water binary interactions parameters are reported in Table 4. The CPA-EoS binary interaction parameters for $\mathrm{O}_{2}-$ water and $\mathrm{Ar}-$ water are listed in Table 5, the parameters for $\mathrm{N}_{2}$ - water and $\mathrm{CO}_{2}$-water were reported in previous works (Chapoy et al., 2012; Haghighi et al., 2009).

\subsection{Density Calculation}

In this work, the volume for $\mathrm{CO}_{2}$ or a $\mathrm{CO}_{2}$-rich mixture calculated by the SRK-EoS is corrected using the exact volume of $\mathrm{CO}_{2}$ at the given $\mathrm{T}$ and $\mathrm{P}$.

$\mathrm{V}^{\text {new }}=\mathrm{V}^{\text {EoS }}-\mathrm{V}^{\mathrm{C}}$

Where $V^{E o S}$ is the molar volume obtained from the equation of state. The correction of molar volume in the Eq. (5), $V^{c}$, is defined as:

$V^{C}=\sum_{k=1}^{N} \mathrm{x}_{\mathrm{i}} \mathrm{V}_{\mathrm{i}}^{\mathrm{C}}$

$x_{i}$ is the composition of component $i$ in the phase in which the volume is calculated. For $\mathrm{CO}_{2}$, $V_{i}^{c}$ is defined by

$$
V_{C O_{2}}^{c}=V_{P_{\text {ure }}}^{\text {EOS }} \mathrm{CO}_{\mathrm{n}}-\mathrm{V}^{\mathrm{MBWR}}
$$


For the other components, $V_{i}^{c}$ is set to 0 . The carbon dioxide density is computed from the MBWR equation in the form suggested by Ely et al. (1987):

$$
P=\sum_{n=1}^{9} a_{n}(T) \rho^{n}+\sum_{n=10}^{15} a_{n}(T) \rho^{2 n-17} e^{-\gamma \rho^{2}}
$$

\subsection{Viscosity Model}

The proposed model is a modification of the corresponding state viscosity model described in Pedersen and Christensen (2007) . According to the corresponding states principles applied to viscosity, the reduced viscosity, $\eta_{r_{s}}=\frac{\eta\left(P_{0} I^{2}\right)}{\eta_{e}}$, for two components at the same reduced pressure, $P_{r}=\frac{P}{P_{c}}$, and reduced temperature, $T_{r}=\frac{T}{T_{c}}$, will be same.

$\eta_{\mathrm{r}}=\mathrm{f}\left(\mathrm{P}_{\mathrm{r}}, \mathrm{T}_{\mathrm{r}}\right)$

Based on the dilute gases considerations, viscosity at critical point can be approximated as:

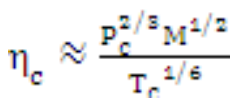

Where, $\mathrm{M}$ denotes the Molecular weight. Thus, the reduced viscosity can be expressed as:

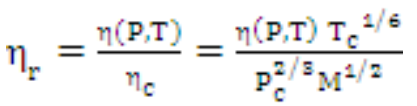

For one component as a reference component if the function $f$ in Eq. (9) is known, it is possible to calculate the viscosity of any other components, such as component $x$, at any pressure and temperature. Thus,

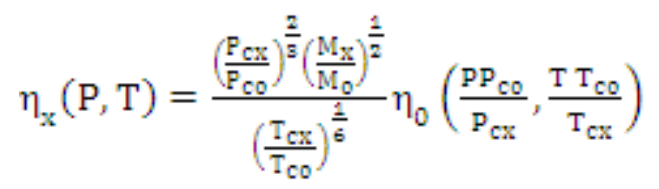


Where, 0 refers to the reference component. Methane with the viscosity data published by Hanley et al. (1975) was selected as the reference fluid in the original Pedersen Model.

In this work, $\mathrm{CO}_{2}$ with the viscosity data published by Fenghour et al. (1998) has been selected as the reference fluid. The viscosity of $\mathrm{CO}_{2}$ as a function of density and temperature can be calculated from the following equation:

$\eta(\rho, T)=\eta_{0}(T)+\Delta \eta(\rho, T)$

Where, $\eta_{0}(T)$ is the zero-density viscosity and can be obtained from the following equation:

$\eta_{0}(T)=\frac{1.00697 \mathrm{~T}^{1 / 8 \mathrm{x}}}{\mathbb{q}_{\mathrm{T}_{0}^{*}}^{*}\left(\mathrm{~T}^{*}\right)}$

In this equation, the zero-density viscosity is in units of $\mu \mathrm{Pa} . \mathrm{S}$ and temperature, $T$, in $\mathrm{K}$. The reduced effective cross section, $\Psi_{\eta_{\eta}}^{8}\left(\mathrm{~T}^{8}\right)$, is represented by the empirical equation:

$\ln \Psi_{x y}^{8}\left(\mathrm{~T}^{8}\right)=\sum_{\mathrm{i}=0}^{4} \mathrm{a}_{\mathrm{i}}\left(\ln \mathrm{T}^{8}\right)^{\mathrm{i}}$

Where the reduced temperature, $\mathrm{T}^{*}$, is given by

$\mathrm{T}^{8}=\mathrm{kT} / \varepsilon$

And the energy scaling parameter, $\frac{\Sigma}{\mathrm{k}}=251.196 \mathrm{~K}$. The coefficients $a_{i}$ are listed in Table 6 . The second contribution in Eq. (13) is the excess viscosity, $\Delta \eta(\rho, T)$, which describes how the viscosity can change as a function of density outside of the critical region. The excess viscosity correlation can be correlated as follows:

$\Delta \eta(\rho, T)=d_{11} \rho+d_{21} \rho^{2}+\frac{d_{B 4} \rho^{6}}{T^{8 I}}+d_{81} \rho^{8}+\frac{d_{g x} \rho^{g}}{T^{2}}$

Where, the temperature is in Kelvin, the density in $\mathrm{kg} / \mathrm{m}^{3}$ and the excess viscosity in $\mu$ Pa.s. The coefficients $d_{i j}$ are shown in Table 7. The corresponding states principle expressed in Eq. (12) for the viscosity of pure components works well for mixtures. Pedersen et al. (1984) have expressed the following expression to calculate the viscosity of mixtures at any pressure and temperature. 


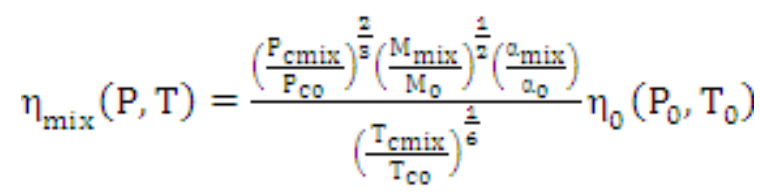

Where

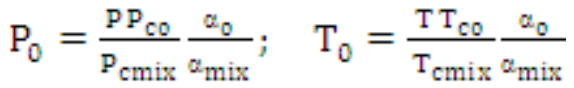

The critical temperature and pressure for mixtures, according to recommended mixing rules by Murad and Gubbins (1977)Erreur ! Source du renvoi introuvable., can be found from:

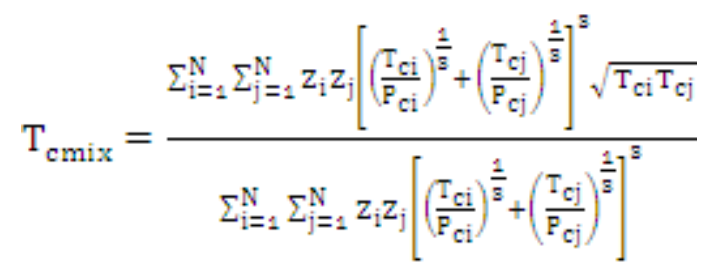

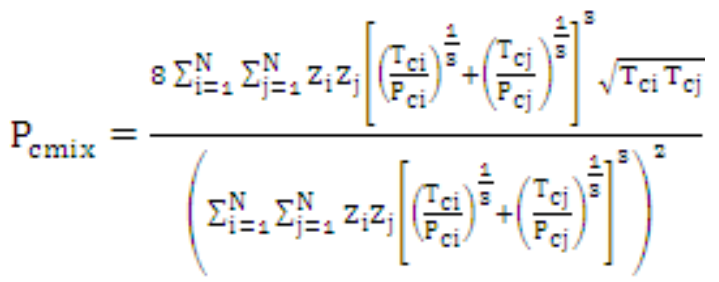

The mixture molecular weight is found from

$\mathrm{M}_{\text {mix }}=1.304 \times 10^{-4}\left(\overline{\mathrm{M}}_{\mathrm{w}}{ }^{2.303}-\overline{\mathrm{M}}_{\mathrm{n}}^{2303}\right)+\overline{\mathrm{M}}_{\mathrm{n}}$

where $\overline{\mathrm{M}}_{\mathrm{w} w}$ and $\overline{\mathrm{M}}_{\mathrm{n}}$ are the weight average and number average molecular weights, respectively.

$$
\begin{aligned}
& \overline{\mathrm{M}}_{\mathrm{w} w}=\frac{\sum_{\mathrm{i}=1}^{\mathrm{N}} \mathrm{z}_{\mathrm{i}} \mathrm{M}_{\mathrm{i}}^{\mathrm{z}}}{\sum_{\mathrm{i}=1}^{\mathrm{N}} \mathrm{z}_{\mathrm{i}} \mathrm{M}_{\mathrm{i}}} \\
& \overline{\mathrm{M}}_{\mathrm{n}}=\sum_{\mathrm{i}=1}^{\mathrm{N}} \mathrm{Z}_{\mathrm{i}} \mathrm{M}_{\mathrm{i}}
\end{aligned}
$$

The parameter $\alpha$ for mixtures in Eq. (19) can be found from

$$
\alpha_{\operatorname{mix}}=1.000+7.378 \times 10^{-3} \rho_{\mathrm{r}}^{1.847} \mathrm{M}_{\operatorname{mix}}^{0.5173}
$$

Also, $\alpha$ for the reference fluid can be found from the Eq. (25) by replacing the molecular weight of the mixture with that of the reference fluid, carbon dioxide. The reduced density, $P_{r}$, is defined as 


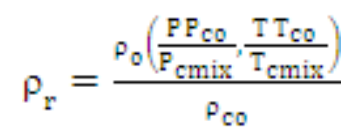

The critical density of carbon dioxide, $\rho_{\mathrm{co}}$, is equal to $467.69 \mathrm{~kg} / \mathrm{m}^{3}$. The Modified BenedictWebb-Rubin (MBWR) equation of state would be applied for computing the reference fluid density, $\mathrm{P}_{0}$, at the desired pressure and temperature of $\frac{\mathrm{PP}_{\mathrm{CB}}}{\mathrm{P}_{\mathrm{cmix}}}, \frac{\mathrm{TT}_{\mathrm{CD}}}{\mathrm{T}_{\mathrm{Cmix}}}$. The mathematical equation of the MBWR has been presented by Ely et al. (1987).

The procedure below should be followed to calculate the viscosity of $\mathrm{CO}_{2}$ systems with impurities by the proposed corresponding state principle model:

1. Calculate the $\mathrm{T}_{\text {cmix }}, \mathrm{P}_{\text {cmix }}$ and $\mathrm{M}_{\text {mix }}$ from Eq. (20), (21) and (22) respectively.

2. Obtain the $\mathrm{CO}_{2}$ density at $\frac{\mathrm{PP}_{\mathrm{CD}}}{\mathrm{P}_{\mathrm{cmix}}}, \frac{\mathrm{TT}_{\mathrm{CO}}}{\mathrm{T}_{\mathrm{Cmix}}}$ from the MBWR EOS and calculate the reduced density from Equation (26)

3. The mixture parameter, $\alpha_{\text {mix }}$, and $\alpha_{0}$ should be calculated from Eq. (25)

4. The reference pressure and temperature, $\mathrm{P}_{0}$ and $\mathrm{T}_{0}$, should be calculated from Equation (19)

5. Calculate the $\mathrm{CO}_{2}$ reference fluid, $\eta_{0}\left(\mathrm{P}_{0}, \mathrm{~T}_{0}\right)$, in Eq. (18) from Eq. (13)

6. Calculate the mixture viscosity from Eq. (18)

\section{Results and discussions}

\subsection{Phase Envelope}

Bubble point measurements were carried out for the multicomponent mixture from about 253 to about $283 \mathrm{~K}$. The results are listed in Table 8 and plotted in Figure 5. As seen in Figure 5, the SRK-EoS model can predict the phase envelope of the multi component systems with good accuracy, the predictions are in better agreement at higher temperature. The predicted critical temperature and pressure are $296.9 \mathrm{~K}$ and 8.79 MPa, respectively.

\subsection{Hydrate Stability}

The experimental hydrate dissociations for the mixture in equilibrium with water are reported in Table 9 and plotted in Figure 6 along with the prediction of the dry multicomponent mixture phase envelope and the pure $\mathrm{CO}_{2}$ hydrate stability zone. As seen in the figure, we 
have first a vapour + hydrate + liquid water line, then a vapour +liquid rich $\mathrm{CO}_{2}+$ hydrate + liquid water line and finally a liquid rich $\mathrm{CO}_{2}+$ hydrate + liquid water line. The bubble point of the mixture is higher than pure $\mathrm{CO}_{2}$, hence hydrates would be more stable in the liquid region, as the vapour +liquid rich $\mathrm{CO}_{2}+$ hydrate + liquid water line is intersecting the bubble line at higher temperature.

For this system the thermodynamic model is in excellent agreement with the new experimental data in the vapour phase region and within $0.5-0.8 \mathrm{~K}$ above the dew line. The ratio between the water mole fraction and the mixture fraction has a limited effect in this range of aqueous fraction as nitrogen, oxygen and argon are weak hydrate former. It is also interesting to note that the hydrate stability zone of the multicomponent mixture is more stable than any of the pure constituent of the mixture above the bubble line.

\subsection{Water content in equilibrium with hydrates}

The experimental data for the pure $\mathrm{CO}_{2}$ and the multicomponent systems are presented in Table 10 and plotted along with predictions of the thermodynamic model (descriptions given in next section) in Figure 7. As can be seen from the figure the experimental and predicted data are in good agreement with some deviation $(\mathrm{AAD} \approx 5 \%)$. As expected it can seen that for the multicomponent system less water can be dissolved than in pure $\mathrm{CO}_{2}$, because the amount of water that can be dissolved in nitrogen, oxygen or argon is far lower at same temperature and pressure than in liquid $\mathrm{CO}_{2}$. The water content is in average about $10-30 \%$ lower with these impurities than in pure $\mathrm{CO}_{2}$.

\subsection{Viscosity}

The experimental and modelling results for the viscosity of the stream are given in Table 11, Figure 8 and Figure 9. All experiments for the stream were conducted at pressures above saturation or in the supercritical region and then at low pressures, i.e., in the single gas phase region. Then, the viscosity of each conducted test was calculated using the modified Pedersen 
model. The results are also shown in Tables 11. As can be seen from the table, the model predictions and experimental data are in good agreement. The Absolute Average Deviation (AAD) is $1.7 \%$.

\subsection{Density}

Densities of this multi component mixture with $10 \%$ impurity were measured at different pressures and temperatures in gas, liquid and supercritical regions. Both experimental and modelling results with and without density correction are shown in Table 12, Figure 10 and Figure 11. In addition the Absolute Average Deviations (AADs) for all data are listed in the table. As can be seen, by employing density correction using SRK-EoS the absolute average deviation reduces from $5.4 \%$ to $1.7 \%$.

It is interesting to note the peculiar behaviour of the density at temperature above the critical temperatures compared to the density of pure $\mathrm{CO}_{2}$ as seen in Figure 12 in which the difference between the density of the multicomponent mixture and pure $\mathrm{CO} 2$ peaks is plotted at $323.48 \mathrm{~K}$. A maximum reduction of the $\mathrm{CO}_{2}$ capacity at a certain pressure under the given temperature is observed for the $\mathrm{CO}_{2}$ mixtures. The maximum reduction is $180 \mathrm{~kg} / \mathrm{m} 3$ at a pressure around $12 \mathrm{MPa}$.

\section{Conclusion}

Knowledge on how impurities/contaminants impacts the phase behaviour and the thermophysical properties of $\mathrm{CO}_{2}$ rich systems is currently of great importance for the deployment of CCS. As discussed in this work, no data sets are available for such systems. In this communication impact of impurities on the phase behaviour and thermophysical properties of a CO2-rich stream have been studied on

(i) The phase envelope of the stream from 253 to $293 \mathrm{~K}$

(ii) The hydrate stability of a CCS stream up to about $35 \mathrm{MPa}$ 
(iii) The dehydration requirement

(iv) The viscosity and density of the mixture

(v) Models have been developed to calculate and predict these properties 


\section{Acknowledgements}

This work is part of an ongoing Joint Industrial Project (JIP) conducted jointly at the Institute of Petroleum Engineering, Heriot-Watt University and the CTP laboratory of MINES ParisTech. The JIP is supported by Chevron, GALP Energia, Linde AG, OMV, Petroleum Expert, Statoil, TOTAL and the UK National Grid, which is gratefully acknowledged. The authors would also like to thank the members of the steering committee for their fruitful comments and discussions. 


\section{References}

Chapoy, A., Burgass, R., Tohidi, B., Austell, J.M., Eickhoff, C., 2011. Effect of Common Impurities on the Phase Behavior of Carbon-Dioxide-Rich Systems: Minimizing the Risk of Hydrate Formation and Two-Phase Flow. SPE J. 16, 921-930 (document ID SPE-123778-PA)

Chapoy, A., Haghighi, H., Burgess, R., Tohidi, B. 2012. On the Phase Behaviour of the Carbon Dioxide - Water Systems at Low Temperatures: Experimental and Modelling. J. Chem. Therm. 47, 6-12.

De Visser, E., Hendricks, C., Barrio, M., Molnvik, M. J., de Koeijer, G., Liljemark, S., Le Gallo, Y., 2008. Dynamis CO2 quality recommendations. International Journal of Greenhouse Gas Control. 2, 478 - 484.

Ely, J.F., Magee, J.W., Haynes, W.M., 1987. Thermophysical properties for special high CO2 content mixtures. Research Report RR-110, Gas Processors Association, Tulsa, OK.

Fenghour, A., Wakeham, W.A., Vesovic, V., 1998. The Viscosity of Carbon Dioxide. J. Phys. Chem. Ref. Data. 27, 31-44.

Haghighi, H., Chapoy, A., Burgess, R., Tohidi, B., 2009. Experimental and thermodynamic modelling of systems containing water and ethylene glycol: Application to flow assurance and gas processing. Fluid Phase Equilib. 276, 24-30.

Hanley, H.J.M., McCarty, R.D., Haynes, W.M., 1975. Equation for the viscosity and thermal conductivity coefficients of methane. Cryogenics 15, 413-417.

Kontogeorgis, G.M., Yakoumis, I.V., Meijer, H., Hendriks, E.M., Moorwood, T., 1999. Multicomponent phase equilibrium calculations for water-methanol-alkane mixtures. Fluid Phase Equilibr. 158, 201-209.

Marshall, D. R., Saito, S., Kobayashi, R. 1964. Hydrates at high pressures: I methane + water, argon + water, and nitrogen + water systems. AIChE J. 10, 202-205.

Murad, S., Gubbins, K.E., 1977. Corresponding states correlation for thermal conductivity of dense fluids. Chem. Eng. Sci., 32, 499-505.

Parrish, W.R., Prausnitz, J.M. 1972. Dissociation pressures of gas hydrates formed by gas mixtures. Ind. Eng. Chem. Process. Des. Develop. 11, 26-34.

Pedersen, K.S., Christensen, P.L., 2007. Phase behaviour of petroleum reservoir fluids. CRC Press, Taylor \& Francis Group. 
Pedersen, K.S., Fredenslund, Aa., Christensen, P.L., Thomassen, P.,1984. Viscosity of crude oils. Chem. Eng. Sci. 39, 1011-1016.

Poling, B.E., Prausnitz, J. M., O’Connell, J. P. 2000. The properties of gases and liquids, 5th ed.; Mc Graw Hill: New York.

Tohidi, B., Burgass, R.W., Danesh, A., Todd, A.C., Østergaard, K.K., 2000. Improving the accuracy of gas hydrate dissociation point measurements, Ann. N.Y. Acad. Sci. 912, 924-931

Van Cleeff, A., Diepen, G. A. M., 1960. Gas hydrate of nitrogen and oxygen, Rec. Trav. Chim. 79, 83-86.

Van der Waals, J.H. Platteeuw, J.C., 1959. Clathrate solutions. Adv. Chem. Phys. 2, 2-57.

Younglove, B.A., Ely, J.F., 1987. Thermophysical Properties of Fluids. II. Methane, Ethane, Propane, Isobutane, and Normal Butane. J. Phys. Chem. Ref. Data, 16, 577-798. 


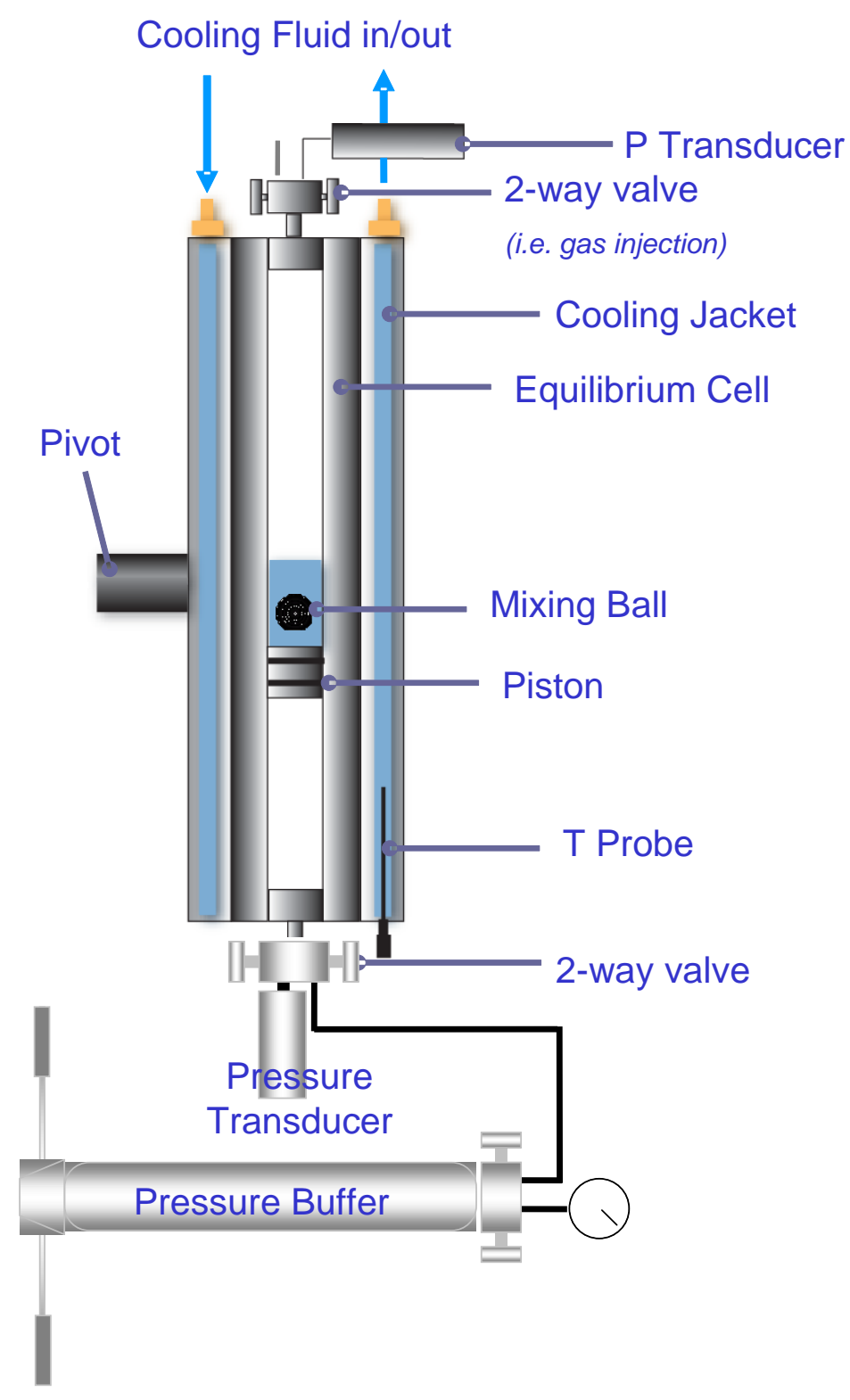

Fig. 1. Schematic illustration of equilibrium rig used for saturation pressure measurements 


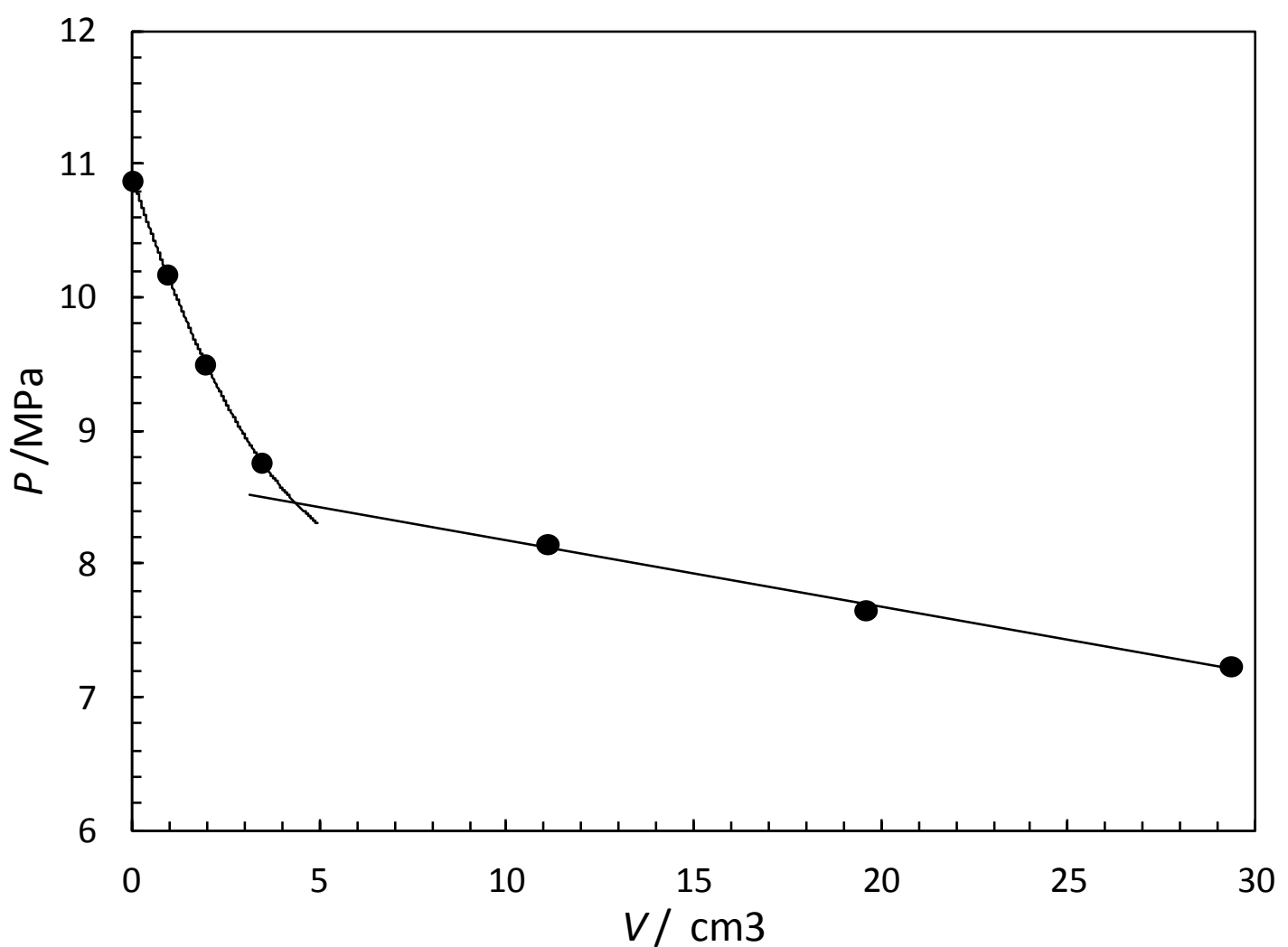

Fig. 2. Plot showing an example of bubble point determination from plot of change in cell pressure, $P$, versus volume, $V$, from test at $283.25 \mathrm{~K}$. As shown in the figure, the measured bubble point pressure at $283.25 \mathrm{~K}$ is $8.48 \mathrm{MPa}$. 


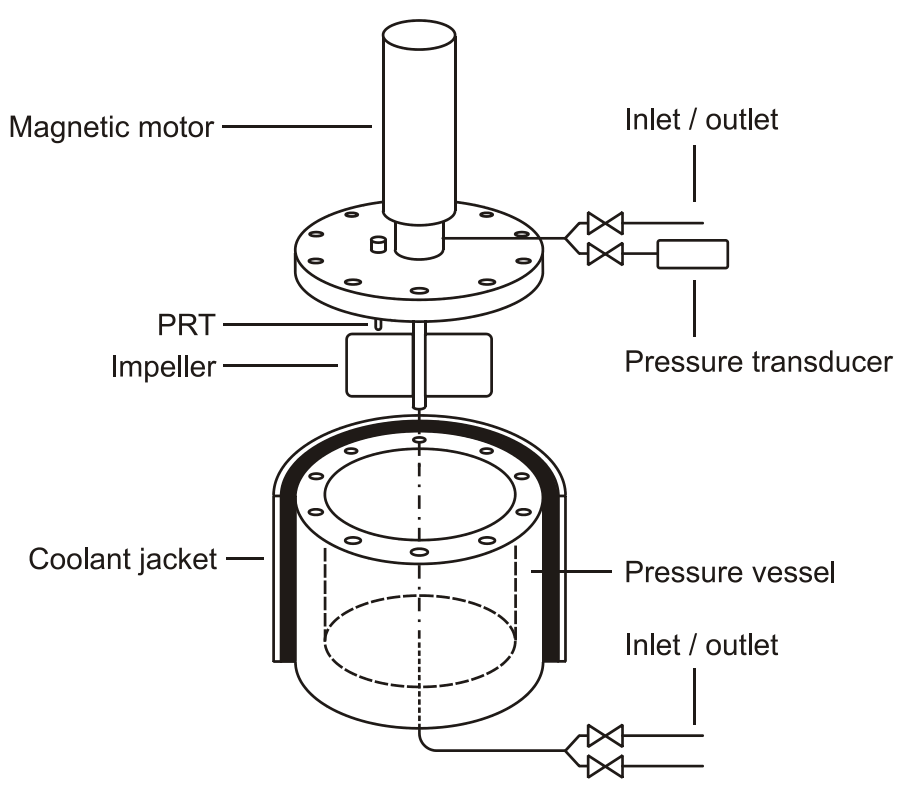

Fig. 3. Schematic illustration of high-pressure hydrate rig 


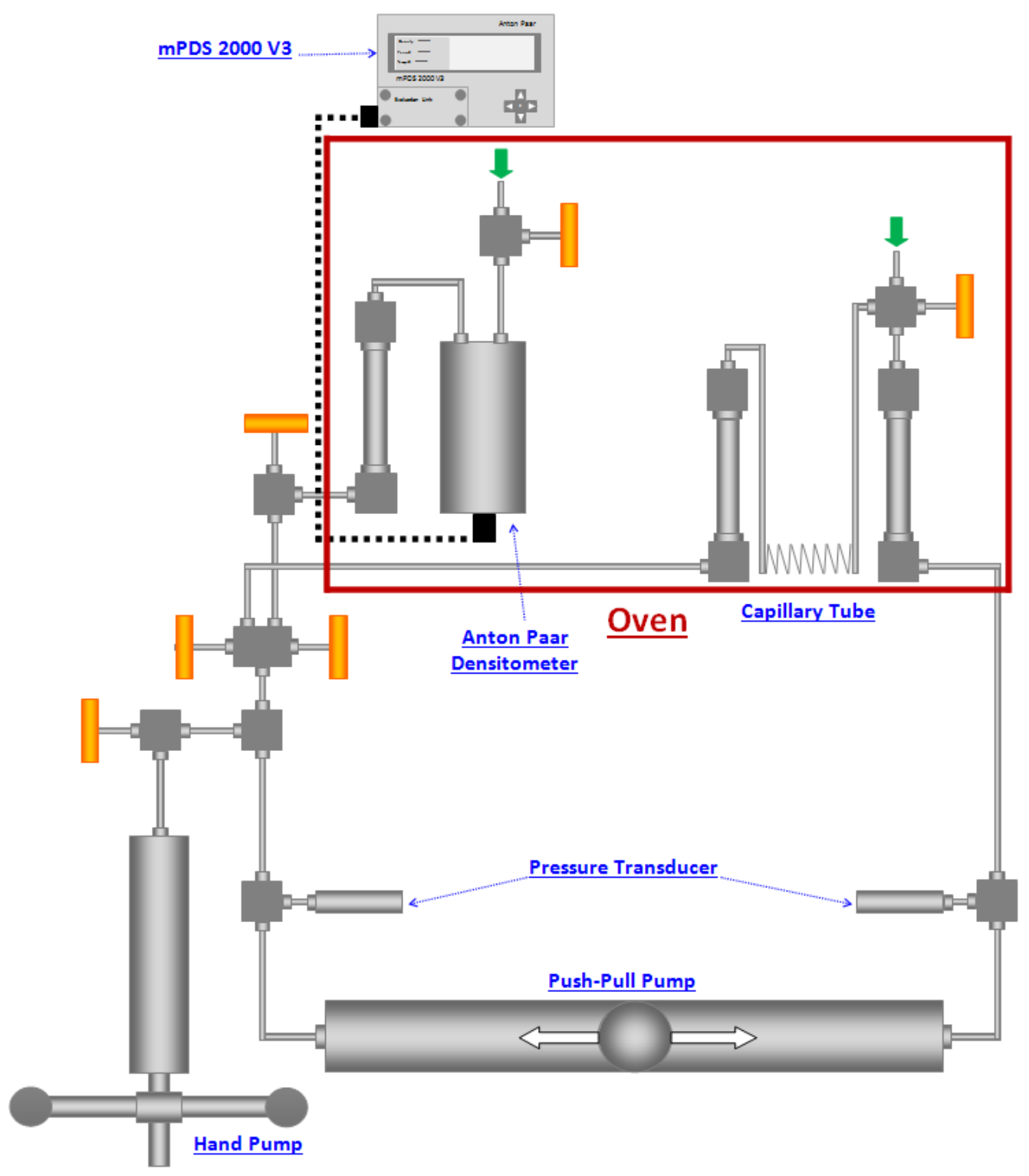

Fig. 4. Schematic drawing of the viscosity - density set-up 


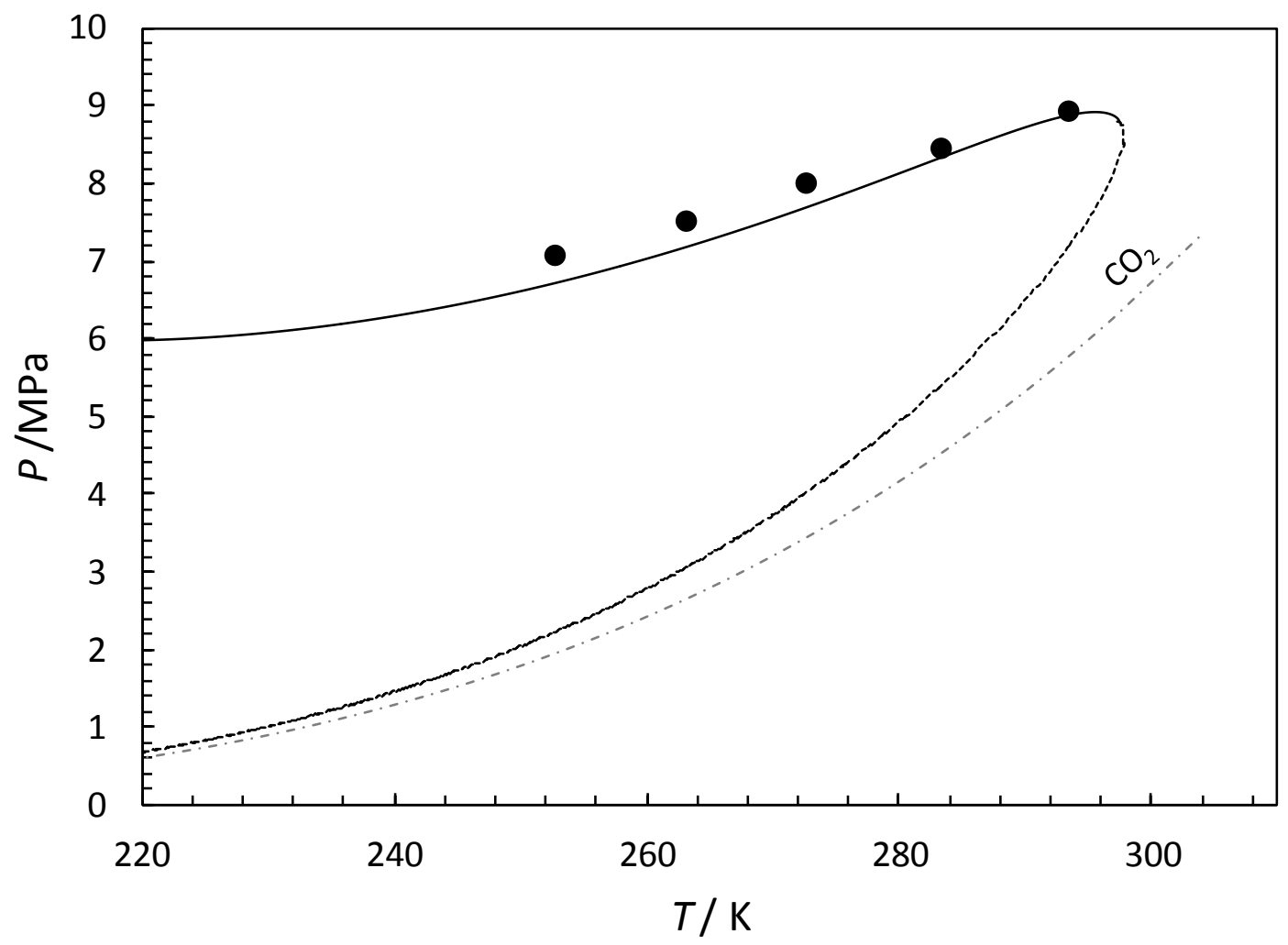

Fig. 5. Experimental and predicted phase envelope of the synthetic mixture. (O), this work. Black lines: bubble lines predictions using the SRK-EoS; Dotted black lines: dew lines predictions using the SRK-EoS; Grey broken lines: predicted vapour pressure of pure $\mathrm{CO}_{2}$ using the SRK-EoS. 


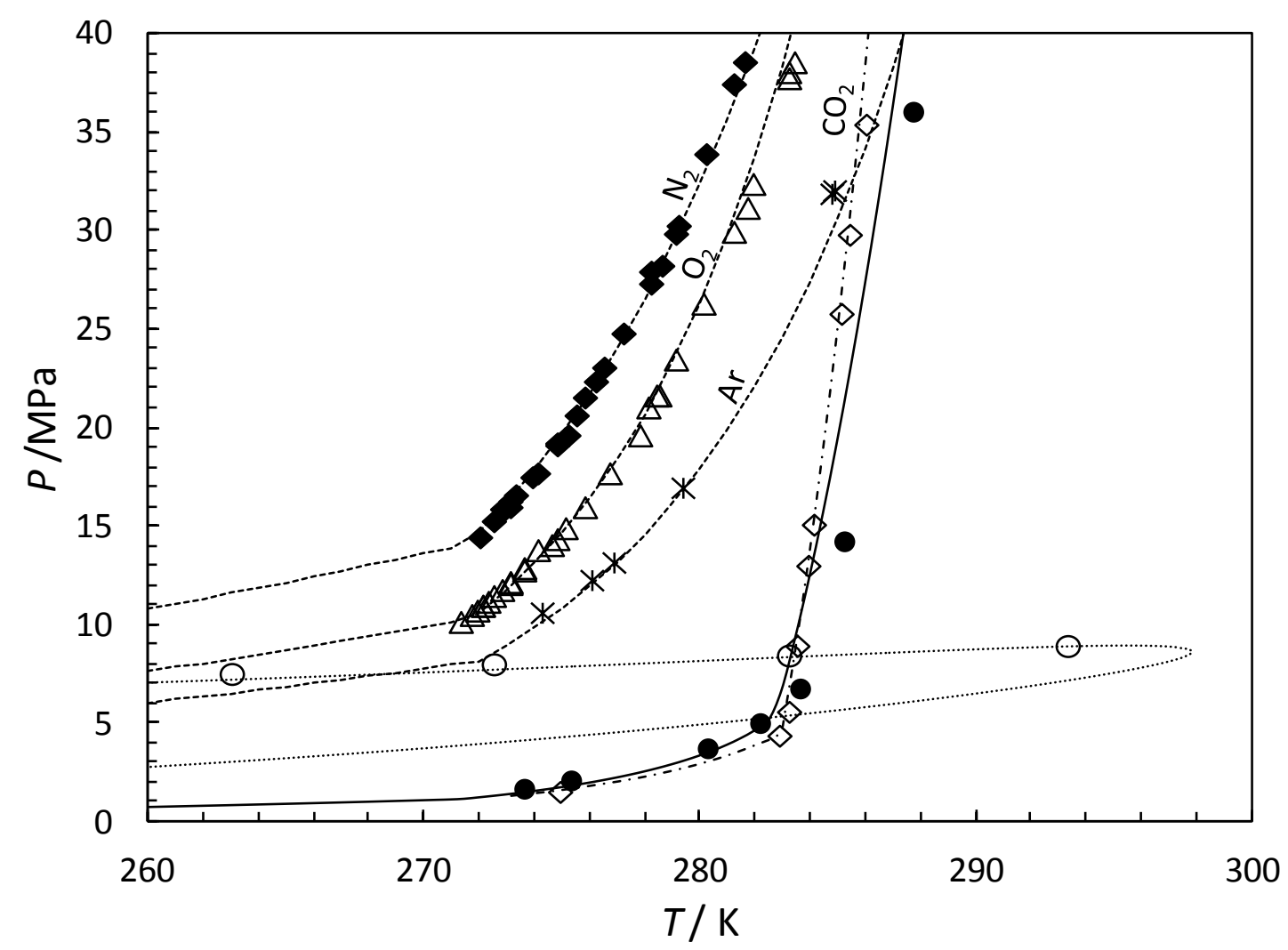

Fig. 6. Predicted and experimental hydrate stability of the $\mathrm{CO}_{2}$-rich stream in presence of distilled water. (-), this work; Black lines: hydrate stability zone predicted using the CPAEoS model using an aqueous mole fraction of $0.8 ;(\bigcirc)$, dry system saturation points, this work; Dotted lines: phase envelope of the dry system (no water) using the SRK-EoS. Broken lines: pure $\mathrm{CO}_{2}$ hydrate stability zone predicted using the CPA-EoS model. $(\diamond)$, pure $\mathrm{N}_{2}$ hydrate stability zone Erreur ! Source du renvoi introuvable.; $(\triangle)$, pure $\mathrm{O}_{2}$ hydrate stability zone Erreur ! Source du renvoi introuvable.; ( $\star$, pure Ar hydrate stability zone (Marshall et al., 1964) $(\diamond)$, pure $\mathrm{CO}_{2}$ hydrate stability zone (Chapoy et al. 2011). 


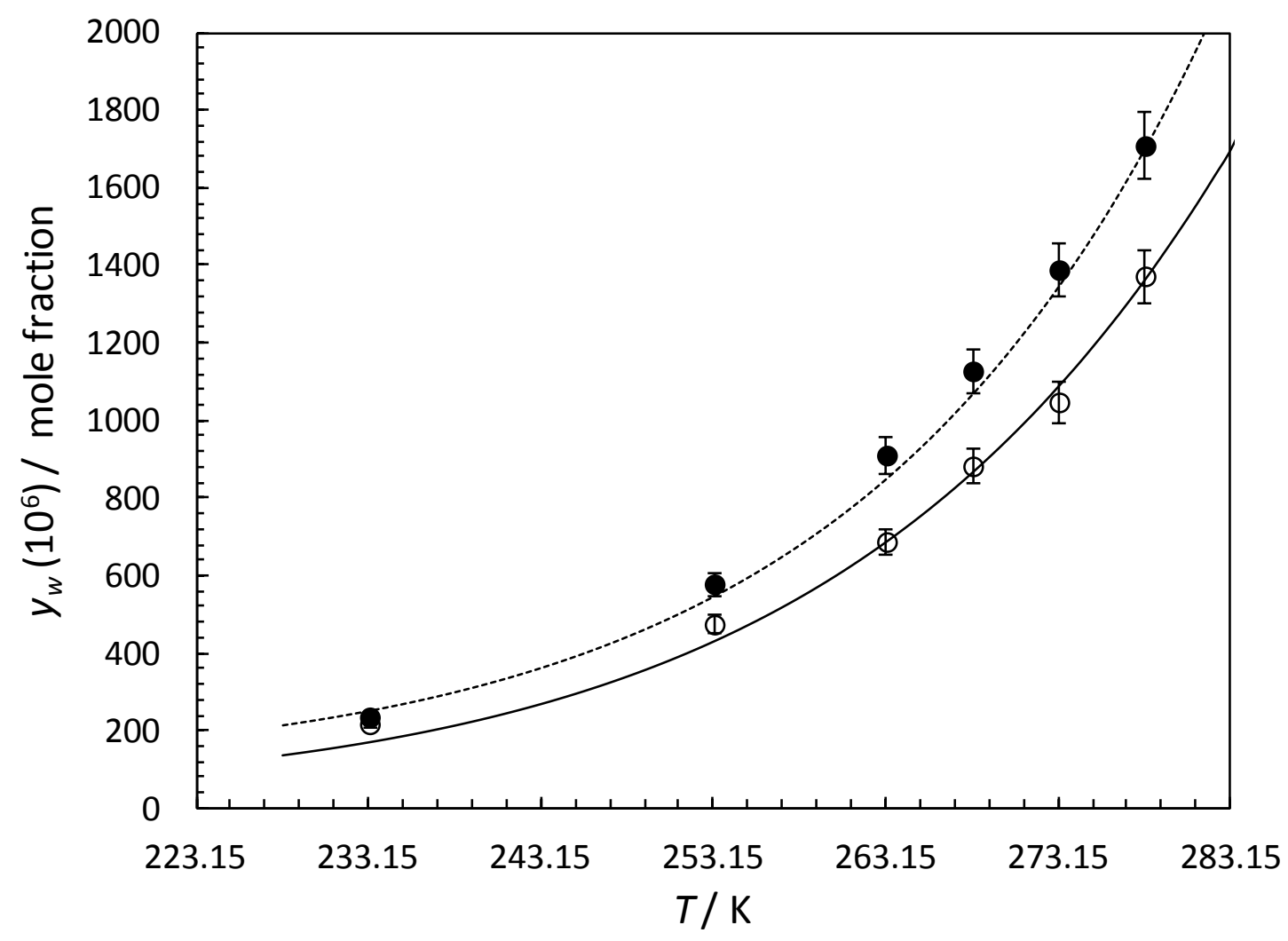

Fig. 7. Plot showing experimental water content data and predictions for the water content of pure $\mathrm{CO}_{2}$ and the $\mathrm{CO}_{2}$-rich stream in equilibrium with hydrates at $15 \mathrm{MPa}$ and different temperatures. ( ), pure $\mathrm{CO}_{2}$, this work; Dotted lines: water content predictions using the CPA-EoS model for pure $\mathrm{CO}_{2} ;(\bigcirc)$, multicomponent system, this work; Black Dotted lines: predictions using the CPA-EoS model for pure the multicomponent system. (Error bars: $\pm 5 \%)$. 


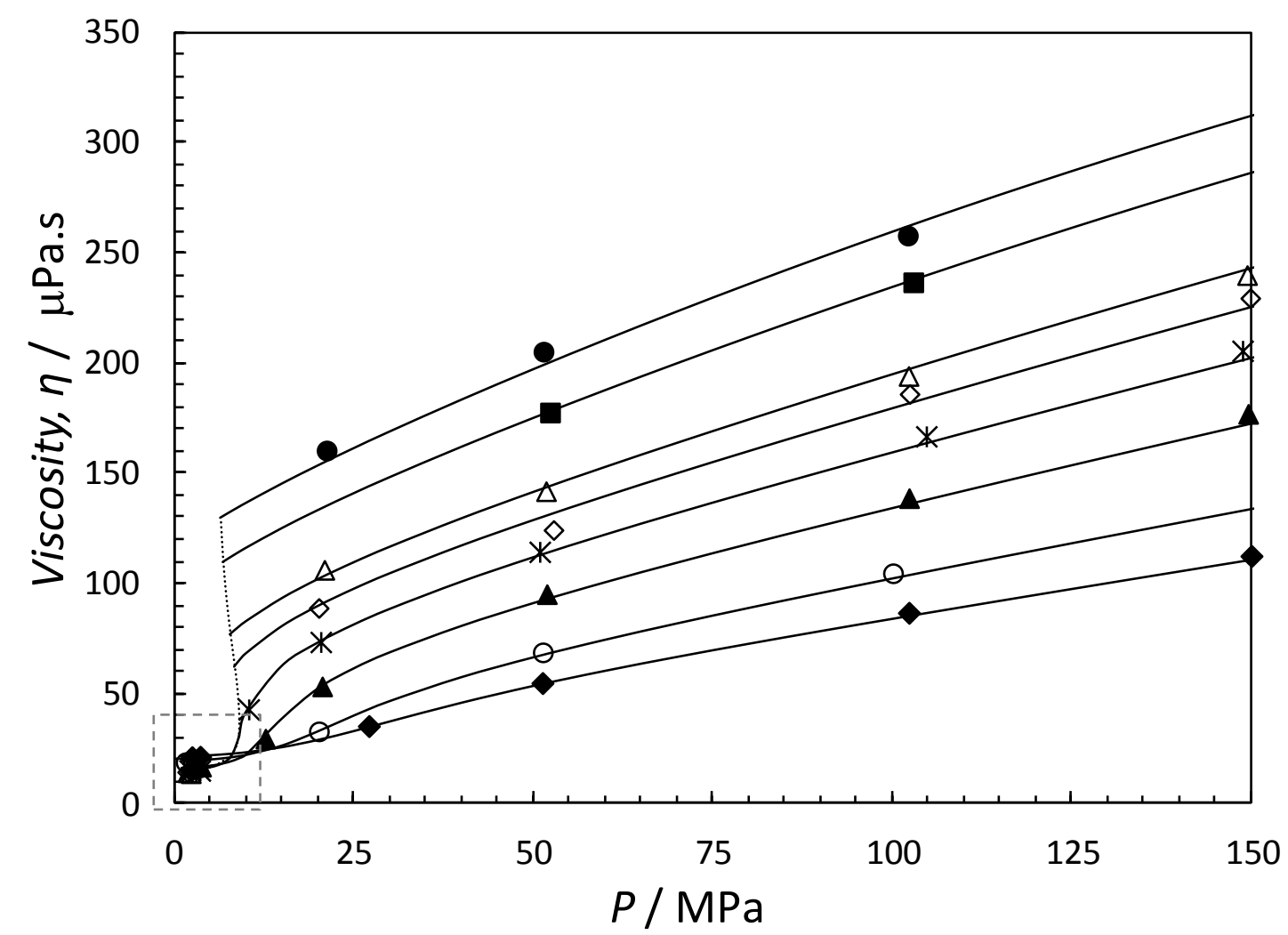

Fig. 8. Predicted and experimental viscosity of the multicomponent $\mathrm{CO}_{2}$-rich stream. Black lines: Predictions using CSP model. Black Dotted lines: Predictions using CSP model at the bubble and dew pressures of the system. Data inside the grey box are plotted in Fig. 9. This work: $(\bigcirc), T=243.15 \mathrm{~K}(\boldsymbol{\square}), T=253.15 \mathrm{~K}(\triangle), T=273.15 \mathrm{~K}(\diamond), T=283.15 \mathrm{~K}(\star), T=$ $298.15 \mathrm{~K}(\mathbf{\Delta}), T=323.15 \mathrm{~K}(\mathrm{O}), T=373.15 \mathrm{~K}(\diamond), T=423.15 \mathrm{~K}$. 


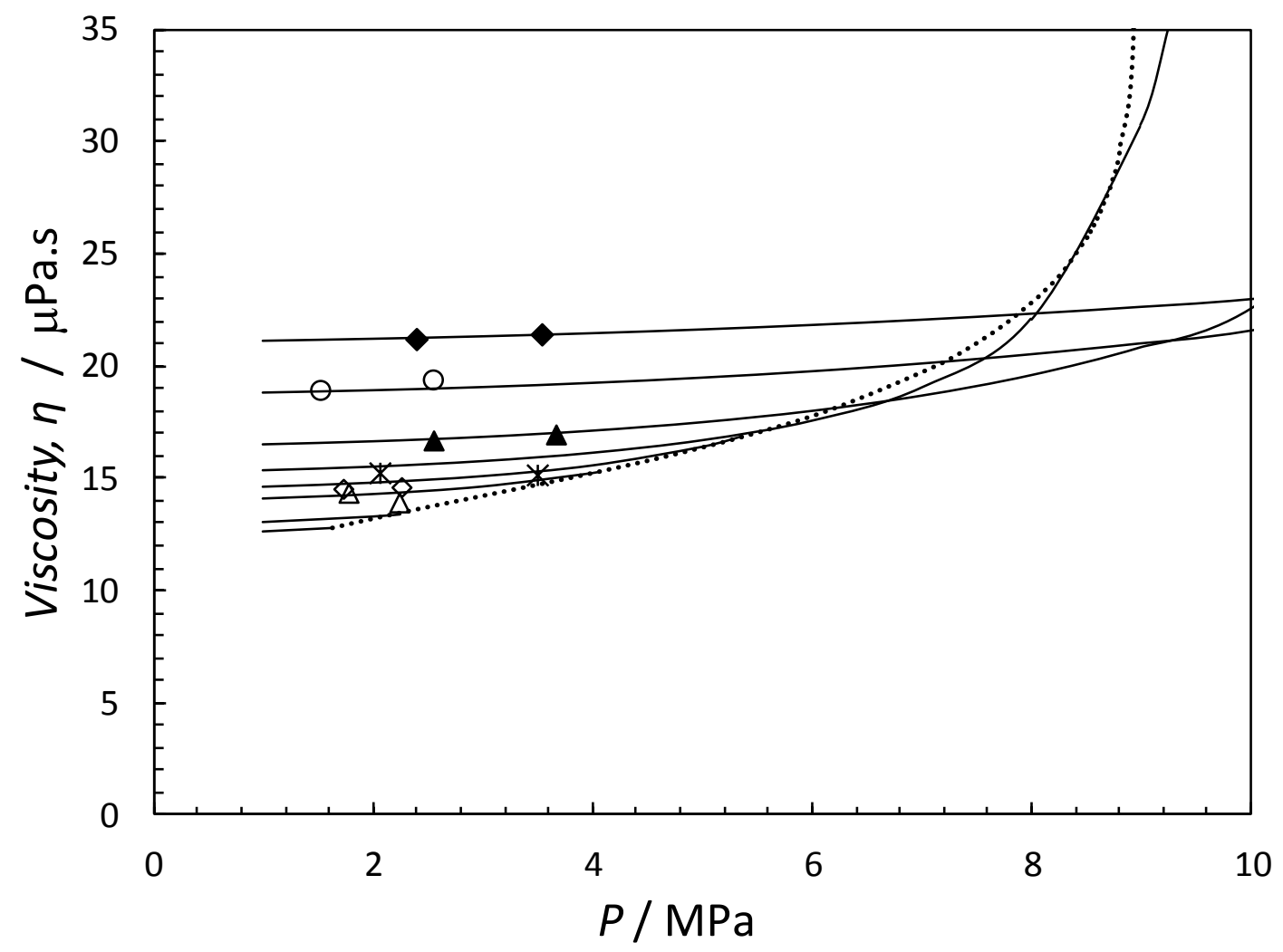

Fig. 9. Predicted and experimental viscosity of the multicomponent $\mathrm{CO}_{2}$-rich stream. Black lines: Predictions using CSP model. Black Dotted lines: Predictions using CSP model at the bubble and dew pressures of the system. This work: $(\triangle), T=273.15 \mathrm{~K}(\diamond), T=283.15 \mathrm{~K}$ $(\star), T=298.15 \mathrm{~K}(\boldsymbol{\Delta}), T=323.15 \mathrm{~K}(\bigcirc), T=373.15 \mathrm{~K}(\diamond), T=423.15 \mathrm{~K}$. 


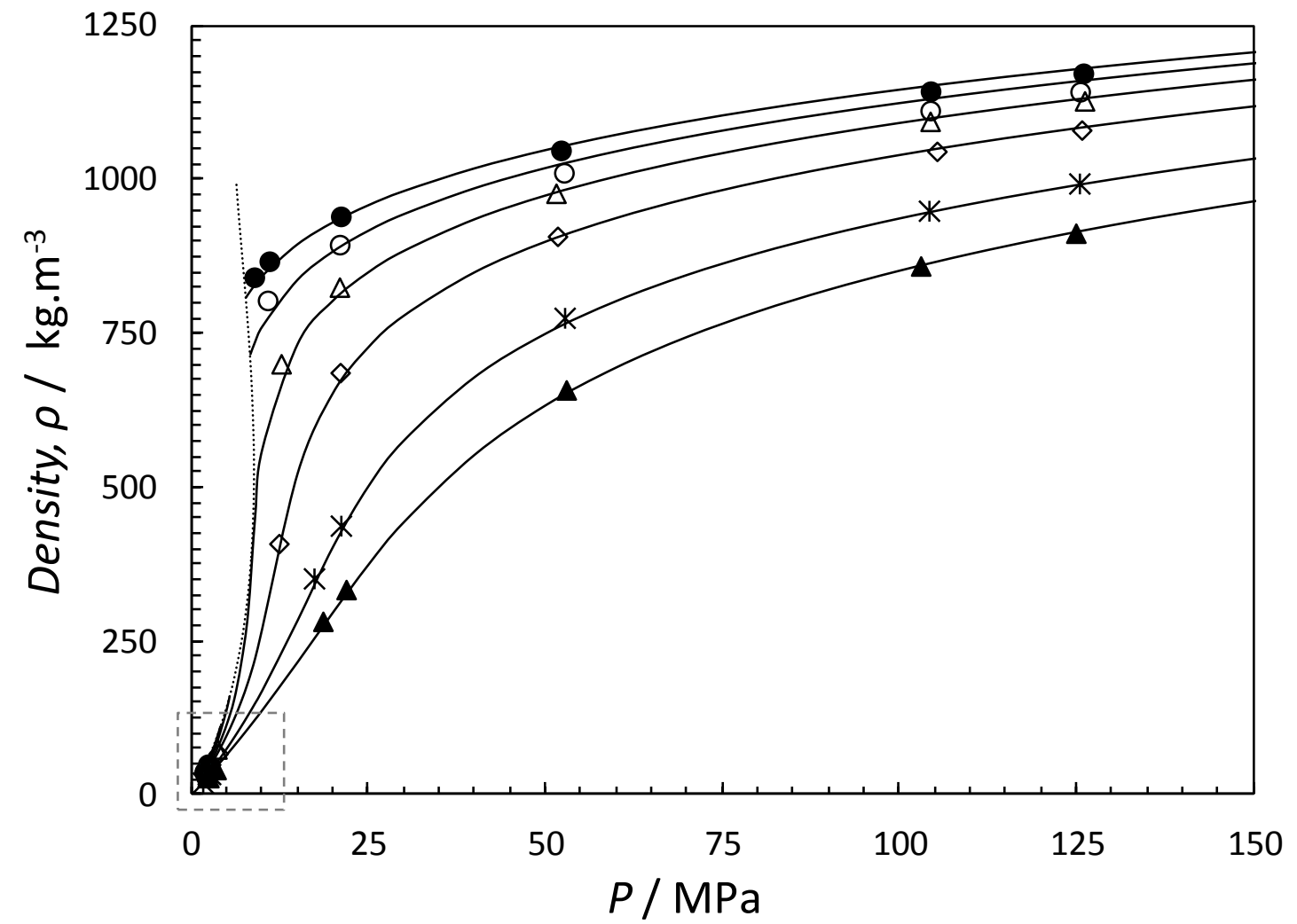

Fig. 10. Predicted and experimental density of the multicomponent $\mathrm{CO}_{2}$-rich stream. Black lines: Predictions using the corrected SRK-EoS model. Black Dotted lines: Predictions using the corrected SRK-EoS model at the bubble and dew pressures of the system. Data inside the grey box are plotted in Fig. 11. This work: $(\bullet), T=273.26 \mathrm{~K}(\bigcirc), T=283.31 \mathrm{~K}(\triangle), T=$ $298.39 \mathrm{~K}(\diamond), T=323.48 \mathrm{~K}(\star), T=373.54 \mathrm{~K}(\boldsymbol{\Delta}), T=423.43 \mathrm{~K}$. 


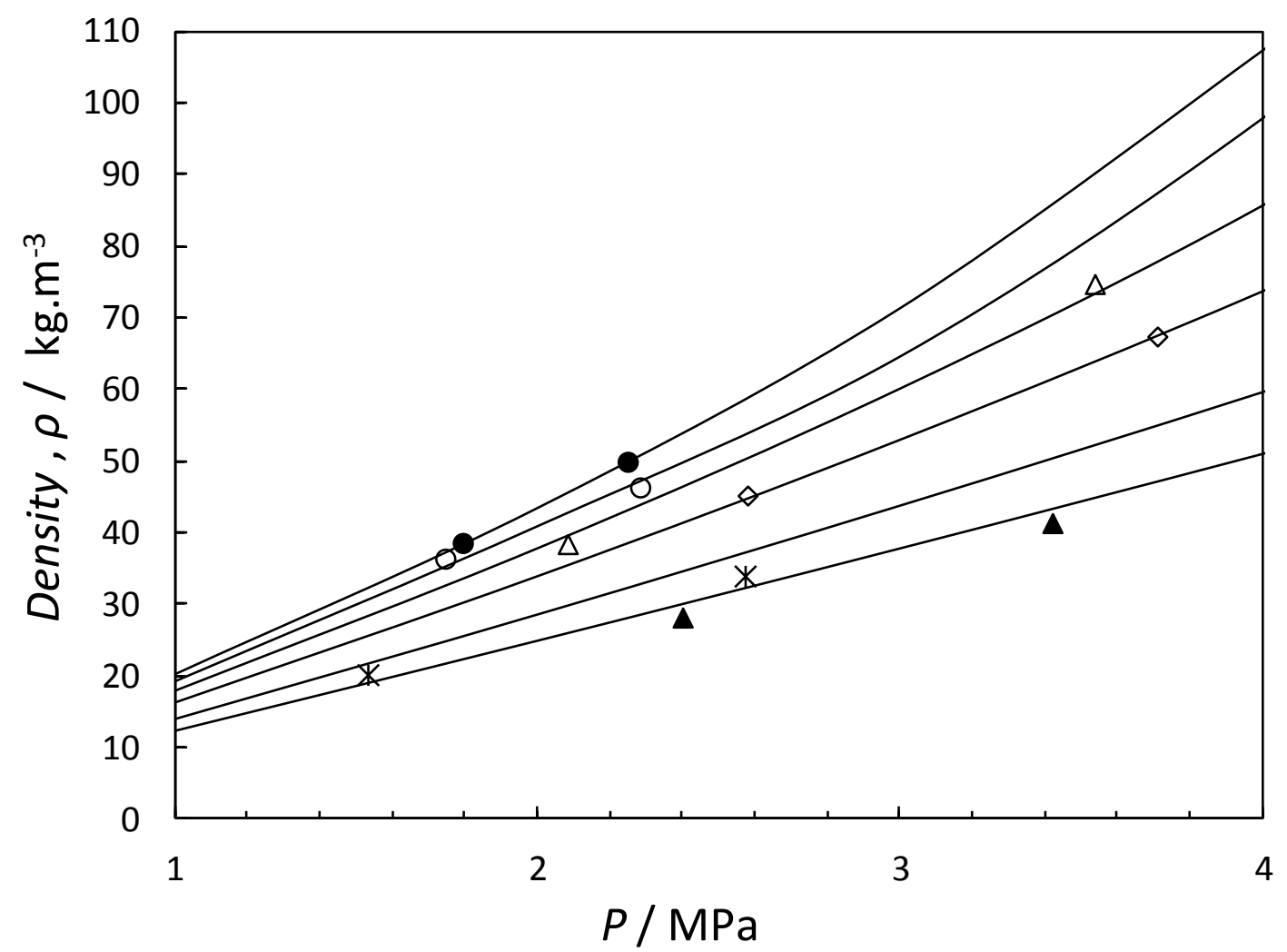

Fig. 11. Predicted and experimental density of the multicomponent $\mathrm{CO}_{2}$-rich stream. Black lines: Predictions using the corrected SRK-EoS model. This work: $(\Theta), T=273.26 \mathrm{~K}(\mathrm{O}), T$ $=283.31 \mathrm{~K}(\triangle), T=298.39 \mathrm{~K}(\diamond), T=323.48 \mathrm{~K}(\star), T=373.54 \mathrm{~K}(\boldsymbol{\Delta}), T=423.43 \mathrm{~K}$. 


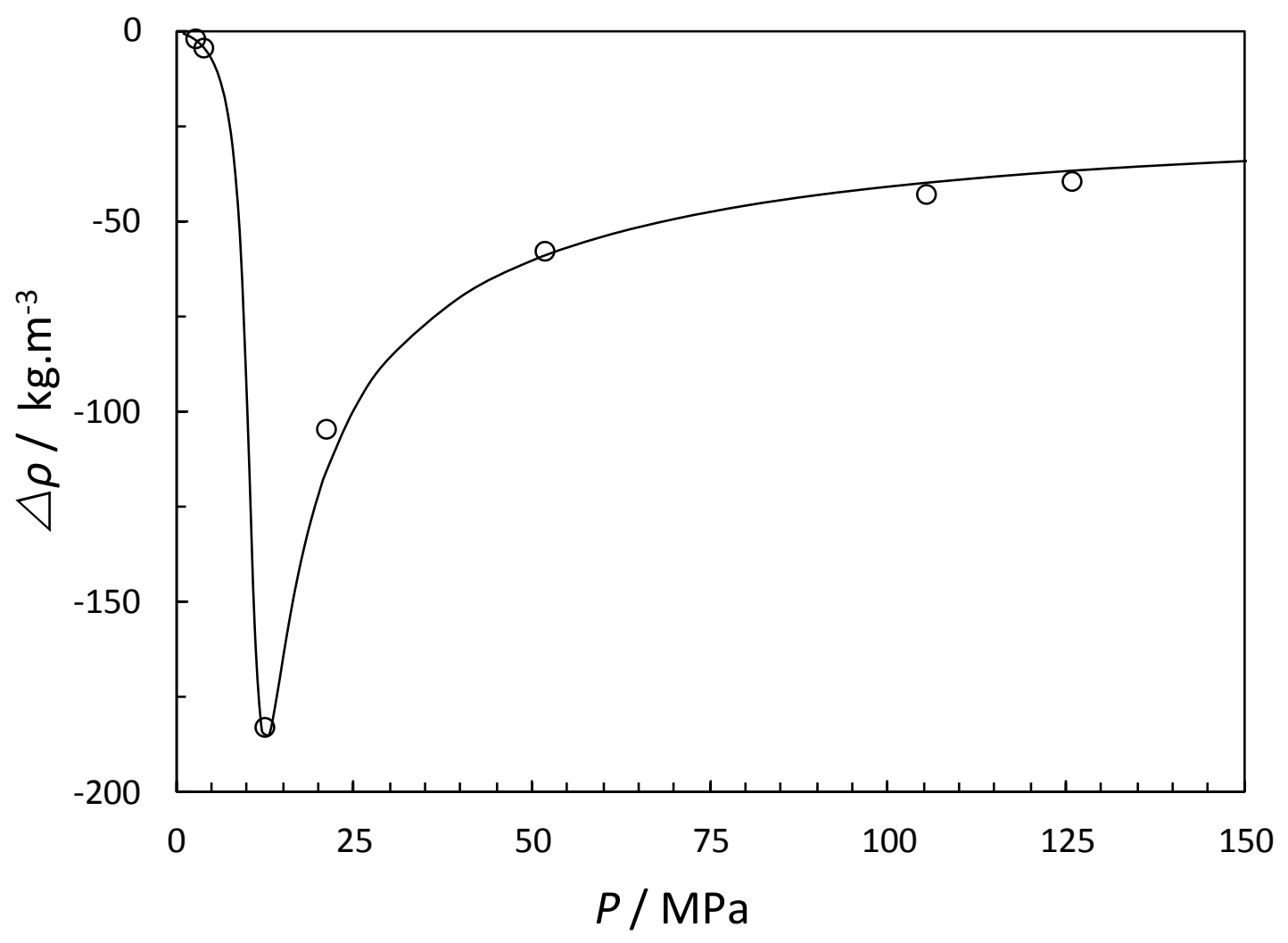

Fig. 12. Predicted and experimental density difference $\Delta \rho=\rho^{M I X}-\rho^{C O 2}$, between the multicomponent $\mathrm{CO}_{2}$-rich stream and pure $\mathrm{CO}_{2}$ density at $323.48 \mathrm{~K}$. Black lines: Predictions using the corrected SRK-EoS model. This work: $(\bigcirc), T=323.48 \mathrm{~K}$. 


\section{Table 1}

Composition, mole\% each component, of the synthetic multicomponent mixture used in this study as prepared and certified by BOC.

\begin{tabular}{cc}
\hline Components & $\begin{array}{c}\text { Composition, } \\
\text { mole\% }\end{array}$ \\
\hline $\mathrm{CO}_{2}$ & Balance \\
$\mathrm{O}_{2}$ & $5.05 \pm 0.1 \%$ \\
$\mathrm{Ar}$ & $2.05 \pm 0.06 \%$ \\
$\mathrm{~N}_{2}$ & $3.07 \pm 0.04 \%$ \\
\hline
\end{tabular}


Table 2

Critical Properties of Pure Compounds (Poiling et al., 2000)Erreur ! Source du renvoi introuvable.Erreur ! Source du renvoi introuvable.

\begin{tabular}{cccc} 
Compound & $P_{c} / \mathrm{MPa}$ & $T_{c} / \mathrm{K}$ & $\omega$ \\
\hline $\mathrm{CO}_{2}$ & 7.386 & 304.21 & 0.2236 \\
$\mathrm{O}_{2}$ & 5.043 & 154.58 & 0.0222 \\
$\mathrm{Ar}$ & 4.898 & 150.86 & -0.0040 \\
$\mathrm{~N}_{2}$ & 3.394 & 126.05 & 0.0403 \\
\hline
\end{tabular}




\section{Table 3}

CPA Parameters for Water (Kontogeorgis et al. 1999).

\begin{tabular}{ccccc}
\hline$a_{0} / \mathrm{MPa} \mathrm{L}^{2} \mathrm{~mol}^{-2}$ & $b / \mathrm{L} \mathrm{mol}^{-1}$ & $c_{l}$ & $\varepsilon / \mathrm{MPa} \mathrm{L} \mathrm{mol}^{-1}$ & $\begin{array}{c}\beta \\
\left(\mathrm{x} 10^{3}\right)\end{array}$ \\
\hline 0.1228 & 0.01452 & 0.6736 & 16.655 & 69.2 \\
\hline
\end{tabular}




\section{Table 4}

Binary interaction parameters between $\mathrm{O}_{2}, \mathrm{Ar}, \mathrm{N}_{2}$ and $\mathrm{CO}_{2}$ for the SRK-EoS and CPA-EoS used in this work.

\begin{tabular}{|c|c|c|c|c|}
\hline & $\mathrm{CO}_{2}$ & $\mathrm{O}_{2}$ & $\mathrm{Ar}$ & $\mathrm{N}_{2}$ \\
\hline $\mathrm{CO}_{2}$ & 0 & 0.106 & 0.123 & -0.03 \\
\hline $\mathrm{O}_{2}$ & & 0 & 0 & -0.014 \\
\hline $\mathrm{Ar}$ & & & 0 & -0.008 \\
\hline $\mathrm{N}_{2}$ & & & & 0 \\
\hline
\end{tabular}




\section{Table 5}

Binary interaction parameters between $\mathrm{O}_{2}, \mathrm{Ar}$, and water for the CPA-EoS .

\begin{tabular}{cc}
\hline System & BIPs \\
\hline O2 - Water & 0.005 \\
$\mathrm{Ar}-$ Water & -0.038 \\
\hline
\end{tabular}


Table 6

Values of Coefficients $a_{i}$ for $\mathrm{CO}_{2}$ in Eq. (15).

\begin{tabular}{ll}
\hline $\mathrm{i}$ & $\mathrm{a}_{\mathrm{i}}$ \\
\hline 0 & 0.235156 \\
1 & -0.491266 \\
2 & $5.211155 \times 10^{-2}$ \\
3 & $5.347906 \times 10^{-2}$ \\
4 & $-1.537102 \times 10^{-2}$ \\
\hline
\end{tabular}




\section{Table 7}

Values of $d_{i j}$ coefficients in Eq. (17)

\begin{tabular}{ll}
\hline$d_{i j}$ & Value \\
\hline$d_{11}$ & $0.4071119 \times 10^{-2}$ \\
$d_{21}$ & $0.7198037 \times 10^{-4}$ \\
$d_{64}$ & $0.2411697 \times 10^{-16}$ \\
$d_{81}$ & $0.2971072 \times 10^{-22}$ \\
$d_{82}$ & $-0.1627888 \times 10^{-22}$ \\
\hline
\end{tabular}




\section{Table 8}

Saturation pressure of the multicomponent mixture.

\begin{tabular}{cc}
$\mathrm{T} / \mathrm{K}^{\mathrm{a}}$ & $\mathrm{P} / \mathrm{MPa}^{\mathrm{b}}$ \\
\hline 252.65 & 7.10 \\
263.05 & 7.54 \\
272.55 & 8.03 \\
283.25 & 8.48 \\
293.35 & 8.96 \\
\hline${ }^{\mathrm{a}}$ Uncertainty on temperature $\mathrm{u}(T)= \pm 0.1 \mathrm{~K}$ \\
${ }^{\mathrm{b}}$ Uncertainty on pressure $\mathrm{u}(P)= \pm 0.03 \mathrm{MPa}$
\end{tabular}




\section{Table 9}

Experimental hydrate dissociation conditions in the presence of distilled water for the multicomponent system (AqFr: aqueous mole fraction in the system).

\begin{tabular}{ccc}
\hline \multirow{2}{*}{ AqFr $^{\mathrm{a}}$} & $\mathrm{T} / \mathrm{K}^{\mathrm{b}}$ & $\mathrm{P} / \mathrm{MPa}^{\mathrm{c}}$ \\
\hline 0.976 & 273.65 & 1.714 \\
0.963 & 275.35 & 2.137 \\
0.948 & 280.30 & 3.768 \\
0.945 & 282.20 & 5.049 \\
0.866 & 283.65 & 6.805 \\
0.730 & 285.25 & 14.279 \\
0.740 & 287.75 & 36.094 \\
\hline${ }^{\mathrm{a}}$ Uncertainty on the aqueous mole fraction $\mathrm{u}(\mathrm{AqFr})= \pm 0.002$ \\
${ }^{\mathrm{b}}$ Uncertainty on temperature $\mathrm{u}(T)= \pm 0.1 \mathrm{~K}$ \\
${ }^{\mathrm{c}}$ Uncertainty on pressure $\mathrm{u}(P)= \pm 0.03 \mathrm{MPa}$
\end{tabular}




\section{Table 10}

Water contents $\left(10^{6}\right.$ mole fraction) for pure $\mathrm{CO}_{2}$ and the multicomponent system in equilibrium with hydrates at $15 \mathrm{MPa}$.

\begin{tabular}{rrr}
\hline \multirow{2}{*}{$\mathrm{T} / \mathrm{K}^{\mathrm{a}}$} & \multicolumn{2}{c}{$\mathrm{Y}_{\mathrm{w}}$, Water } \\
& \multicolumn{2}{c}{ Content $^{\mathrm{b}}$} \\
\cline { 2 - 3 } & \multicolumn{1}{c}{$\mathrm{CO}_{2}$} & \multicolumn{1}{c}{$\mathrm{MIX}$} \\
\hline 288.15 & 2391 & 2010 \\
278.15 & 1711 & 1375 \\
273.15 & 1391 & 1050 \\
268.15 & 1130 & 885 \\
263.15 & 913 & 690 \\
253.15 & 581 & 477 \\
233.15 & 238 & 220 \\
\hline
\end{tabular}

${ }^{\mathrm{a}}$ Uncertainty on temperature $\mathrm{u}(T)= \pm 0.1 \mathrm{~K}$

${ }^{\mathrm{b}}$ Uncertainty on water content $\mathrm{u}\left(y_{w}\right)= \pm 5 \%$ 


\section{Table 11}

Experimental and predicted viscosity, $\eta$ of the multicomponent mixture.

\begin{tabular}{|c|c|c|c|c|}
\hline \multirow{2}{*}{$T / \mathrm{K}^{\mathrm{a}}$} & \multirow{2}{*}{$P / \mathrm{MPa}^{\mathrm{a}}$} & \multicolumn{2}{|c|}{$\eta / \mu \mathrm{Pa} . \mathrm{s}$} & \multirow[b]{2}{*}{$A D$} \\
\hline & & $\operatorname{Exp}^{c}$ & Predicted & \\
\hline 243.15 & 21.15 & 160.5 & 155.6 & $3.0 \%$ \\
\hline 243.15 & 51.35 & 205.3 & 199.8 & $2.7 \%$ \\
\hline 243.15 & 102.10 & 258.0 & 263.4 & $2.1 \%$ \\
\hline 253.15 & 52.27 & 177.7 & 178.9 & $0.7 \%$ \\
\hline 253.15 & 102.86 & 236.8 & 239.3 & $1.0 \%$ \\
\hline 253.15 & 150.89 & 286.6 & 289.2 & $0.9 \%$ \\
\hline 273.15 & 1.77 & 14.4 & 14.2 & $1.0 \%$ \\
\hline 273.15 & 2.23 & 14.0 & 14.4 & $2.9 \%$ \\
\hline 273.15 & 20.84 & 106.3 & 103.6 & $2.5 \%$ \\
\hline 273.15 & 51.71 & 142.0 & 144.1 & $1.5 \%$ \\
\hline 273.15 & 102.20 & 194.3 & 198.2 & $2.0 \%$ \\
\hline 273.15 & 149.35 & 240.1 & 244.0 & $1.6 \%$ \\
\hline 283.15 & 1.72 & 14.6 & 14.7 & $1.0 \%$ \\
\hline 283.15 & 2.25 & 14.6 & 14.8 & $1.3 \%$ \\
\hline 283.15 & 20.05 & 89.0 & 89.7 & $0.8 \%$ \\
\hline 283.15 & 51.54 & 124.4 & 131.1 & $5.4 \%$ \\
\hline 283.15 & 102.34 & 186.1 & 182.4 & $2.0 \%$ \\
\hline 283.15 & 149.80 & 229.6 & 226.3 & $1.4 \%$ \\
\hline 298.15 & 2.05 & 15.3 & 15.5 & $1.4 \%$ \\
\hline 298.15 & 3.49 & 15.2 & 15.9 & $4.7 \%$ \\
\hline 298.15 & 10.30 & 42.9 & 45.3 & $5.4 \%$ \\
\hline 298.15 & 20.33 & 73.5 & 74.1 & $0.8 \%$ \\
\hline 298.15 & 50.83 & 114.5 & 113.2 & $1.1 \%$ \\
\hline 298.15 & 102.77 & 166.9 & 163.1 & $2.2 \%$ \\
\hline 298.15 & 148.72 & 205.7 & 202.4 & $1.6 \%$ \\
\hline 323.15 & 2.54 & 16.7 & 16.7 & $0.2 \%$ \\
\hline 323.15 & 3.66 & 17.0 & 17.0 & $0.3 \%$ \\
\hline 323.15 & 12.62 & 29.7 & 30.7 & $3.4 \%$ \\
\hline 323.15 & 20.53 & 53.4 & 54.1 & $1.3 \%$ \\
\hline 323.15 & 51.82 & 95.2 & 93.4 & $1.9 \%$ \\
\hline 323.15 & 102.27 & 138.8 & 136.8 & $1.5 \%$ \\
\hline 323.15 & 149.50 & 177.1 & 173.2 & $2.2 \%$ \\
\hline 373.15 & 1.51 & 19.0 & 18.9 & $0.4 \%$ \\
\hline 373.15 & 2.54 & 19.4 & 19.0 & $2.1 \%$ \\
\hline 373.15 & 20.07 & 33.0 & 32.8 & $0.4 \%$ \\
\hline 373.15 & 51.26 & 68.8 & 67.7 & $1.6 \%$ \\
\hline 373.15 & 100.03 & 104.7 & 103.0 & $1.7 \%$ \\
\hline 373.15 & 150.53 & 137.1 & 135.3 & $1.3 \%$ \\
\hline 423.15 & 2.39 & 21.2 & 21.2 & $0.1 \%$ \\
\hline 423.15 & 3.53 & 21.4 & 21.4 & $0.4 \%$ \\
\hline 423.15 & 27.03 & 35.4 & 34.7 & $1.9 \%$ \\
\hline 423.15 & 51.21 & 54.9 & 54.6 & $0.5 \%$ \\
\hline 423.15 & 102.25 & 86.8 & 85.9 & $1.0 \%$ \\
\hline \multirow[t]{2}{*}{423.15} & 149.96 & 112.6 & 111.9 & $0.6 \%$ \\
\hline & & & AAD & $1.7 \%$ \\
\hline
\end{tabular}


${ }^{a}$ Uncertainty on temperature $\mathrm{u}(T)= \pm 0.1 \mathrm{~K}$

${ }^{\mathrm{b}}$ Uncertainty on pressure $\mathrm{u}(P)= \pm 0.005 \mathrm{MPa}{ }^{\mathrm{c}}$ Uncertainty on viscosity $\mathrm{u}(\rho)= \pm 1 \%$

\section{Table 12}

Experimental and predicted density of the multicomponent mixture.

\begin{tabular}{|c|c|c|c|c|c|c|}
\hline \multirow[b]{2}{*}{$T / \mathrm{K}^{\mathrm{a}}$} & \multirow[b]{2}{*}{$P / \mathrm{MPa}^{\mathrm{b}}$} & \multicolumn{3}{|c|}{ Density $/ \mathrm{kg} / \mathrm{m}^{3}$} & \multicolumn{2}{|c|}{$A D, \%$} \\
\hline & & Exp. ${ }^{c}$ & $\begin{array}{l}\text { Model with } \\
\text { Correction }\end{array}$ & $\begin{array}{l}\text { Without } \\
\text { Correction }\end{array}$ & $\begin{array}{l}\text { With } \\
\text { Corr. }\end{array}$ & $\begin{array}{c}\text { Without } \\
\text { Corr. }\end{array}$ \\
\hline 273.18 & 1.79 & 38.64 & 38.2 & 37.9 & 1.2 & 1.8 \\
\hline 273.18 & 2.25 & 49.98 & 49.7 & 49.3 & 0.5 & 1.4 \\
\hline 273.27 & 8.81 & 841.98 & 826.8 & 755.7 & 1.8 & 10.2 \\
\hline 273.28 & 10.94 & 867.96 & 855.2 & 785.3 & 1.5 & 9.5 \\
\hline 273.28 & 21.04 & 940.91 & 937.0 & 874.5 & 0.4 & 7.1 \\
\hline 273.29 & 52.14 & $1,048.27$ & $1,053.8$ & $1,005.0$ & 0.5 & 4.1 \\
\hline 273.29 & 104.35 & $1,144.49$ & $1,152.7$ & $1,108.7$ & 0.7 & 3.1 \\
\hline 273.29 & 125.93 & $1,173.60$ & $1,180.8$ & $1,136.5$ & 0.6 & 3.2 \\
\hline 283.31 & 1.74 & 36.44 & 35.0 & 34.9 & 4.0 & 4.1 \\
\hline 283.30 & 2.28 & 46.40 & 47.4 & 47.4 & 2.1 & 2.1 \\
\hline 283.31 & 10.69 & 804.24 & 774.9 & 705.4 & 3.6 & 12.3 \\
\hline 283.31 & 20.88 & 894.93 & 889.6 & 826.3 & 0.6 & 7.7 \\
\hline 283.32 & 52.55 & $1,011.85$ & $1,026.0$ & 978.8 & 1.4 & 3.3 \\
\hline 283.32 & 104.30 & $1,113.02$ & $1,131.0$ & $1,090.3$ & 1.6 & 2.0 \\
\hline 283.31 & 125.48 & $1,143.66$ & $1,160.5$ & $1,119.7$ & 1.5 & 2.1 \\
\hline 298.38 & 2.08 & 38.48 & 39.6 & 39.6 & 3.0 & 2.9 \\
\hline 298.38 & 3.54 & 74.81 & 73.4 & 73.2 & 1.8 & 2.1 \\
\hline 298.38 & 12.60 & 701.23 & 677.6 & 612.4 & 3.4 & 12.7 \\
\hline 298.39 & 20.84 & 825.87 & 812.1 & 748.3 & 1.7 & 9.4 \\
\hline 298.40 & 51.43 & 978.52 & 978.5 & 932.4 & 0.0 & 4.7 \\
\hline 298.40 & 104.29 & $1,095.47$ & $1,098.8$ & $1,062.4$ & 0.3 & 3.0 \\
\hline 298.38 & 126.11 & $1,128.77$ & $1,131.6$ & $1,095.7$ & 0.3 & 2.9 \\
\hline 323.49 & 2.58 & 45.26 & 44.9 & 44.8 & 0.8 & 0.9 \\
\hline 323.50 & 3.71 & 67.48 & 67.6 & 67.5 & 0.2 & 0.0 \\
\hline 323.45 & 12.29 & 408.79 & 398.6 & 358.1 & 2.5 & 12.4 \\
\hline 323.45 & 20.95 & 686.84 & 668.8 & 607.9 & 2.6 & 11.5 \\
\hline 323.48 & 51.65 & 908.44 & 904.3 & 859.7 & 0.5 & 5.4 \\
\hline 323.50 & 105.25 & $1,046.64$ & $1,048.1$ & $1,016.9$ & 0.1 & 2.8 \\
\hline 323.49 & 125.71 & $1,081.30$ & $1,082.7$ & $1,053.1$ & 0.1 & 2.6 \\
\hline 373.49 & 17.25 & 352.26 & 339.7 & 315.9 & 3.6 & 10.3 \\
\hline 373.50 & 21.04 & 438.04 & 427.0 & 390.1 & 2.5 & 11.0 \\
\hline 373.53 & 52.66 & 776.02 & 765.9 & 724.0 & 1.3 & 6.7 \\
\hline 373.55 & 104.12 & 950.13 & 947.8 & 921.5 & 0.2 & 3.0 \\
\hline 373.55 & 125.37 & 994.44 & 992.6 & 969.4 & 0.2 & 2.5 \\
\hline 423.48 & 2.40 & 28.22 & 29.9 & 29.8 & 6.1 & 5.8 \\
\hline 423.49 & 3.42 & 41.42 & 43.2 & 43.0 & 4.3 & 3.7 \\
\hline 423.38 & 18.51 & 282.42 & 269.7 & 255.5 & 4.5 & 9.5 \\
\hline 423.38 & 21.79 & 334.13 & 321.5 & 301.3 & 3.8 & 9.8 \\
\hline 423.41 & 52.88 & 658.74 & 647.0 & 608.6 & 1.8 & 7.6 \\
\hline 423.42 & 102.96 & 860.27 & 856.5 & 831.6 & 0.4 & 3.3 \\
\hline 423.42 & 124.87 & 913.59 & 911.5 & 890.1 & 0.2 & 2.6 \\
\hline & & & & & 1.7 & 5.4 \\
\hline
\end{tabular}

${ }^{\mathrm{a}}$ Uncertainty on temperature $\mathrm{u}(T)= \pm 0.01 \mathrm{~K}$ 
${ }^{\mathrm{b}}$ Uncertainty on pressure $\mathrm{u}(P)= \pm 0.005 \mathrm{MPa}$

${ }^{\mathrm{b}}$ Uncertainty on density $\mathrm{u}(\rho)= \pm 0.74 \%$ 